\title{
The formation of baric depressions near the Alps
}

\author{
A. Speranza $(*)$ \\ Received on July 2nd, 1975
}

Sumvary. - Available knowledge about the formation of baric lows near the $A$ lps is eritically reviewed. Emplasis is laid on problems that require further investigation. A distinction between the process of formation of local depressions in the baric field and real eyclogenesis (generation of (yclonic vorticity) in the lee of the $A l_{p}$ s is suggested on the basis of theoretical considerations about the role of inertial effects in rotating flows past obstacles. Finally, the general inportance of the problem of secondary Hows in the interaction with obstacles is emphasizerl.

Riassunto. - Si riesaminano criticamente le conoseenze sul processo di formazione di zone depressionarie vicino alle Alpi ponendo l'acento sui problemi che richiedono ulteriore analisi. Si propone una distinzione tra il processo di formazione di zone depressionarie e l'autentica ciclogenesi (generazione di vorticita cicloniea) sottovento alle Alpi, sulla base di consilerazioni teoriche sul ruolo degli effetti inerziali nei flussi ruotanti at torno a ostacoli. Si mette infine in evidenza l'importanza generale del problema dei fussi secondari nell'interazione con ostacoli.

\section{Chapter 1}

\subsection{INTKO) (ECTION $(* *)$}

It is well known that the Western Mediterranean is an area of formation of strong depression in the baric field. Particularly relevant

(*) Istituto di Fisica dell Universiti, Venezia; Istituto di Fisica dell'Universita, Bologna.

(**) Note: most of the material contained in this paper was presented in the section of Geoplyysies of the annual meeting of the Italian Physical Society held in Bologna in November 1974. 
are the frequency, duration and intensity of the local pressure-lows in the region immediately South of the barrier of the Alps (Ligurian Sea, Po valley, Northern Arriatic Sea).

Figures 1.1 to 1.4 give a somewhat simplified version of the meteorological maps of pressure (at sea level) at significant stages of the development of a deep Low (19th to 24 th April 1967).

The first figure in the sequence (Fig. 1.1) shows a front of cold air flowing between a large scale Low and a High; the cold air is still over the Atlantic Ocean, but it is progressing towards the Mediterranean. In Fig. 1.2 the same flow of cold air is seen to interact with the mountain chains bordering the North-Eastern Mediterranean (Alps, Pyrenees).

As the interaction of the flow with the topographic obstacles takes place, a local depression develops on the windward side of the Alps (Fig. 1.3) and moves eastward, while being filled (Fig. 1.4).

It is customary in the analysis of large scale, slow motions of the atmospheric fluid to interpret, in the light of quasi-geostrophic theory, the pressure lines as streamlines. The isobars enclosing the minimum of pressure have therefore always been considered as indicative of the presence of a closed circulation in the form of a cyclonic vortex.

The physical phenomenon just described is in fact known as "cyclogenesis in the lee of the Alps". Owing to its impact on the climate of the eastern Mediterranean, it has been the object of a considerable amount of experimental and theoretical investigation.

On the other hand, the constant progress in the numerical prediction of large scale atmospheric motions has brought the problem of flow over and around topographic obstacles to the attention of physicists. In particular, the problem of atmospheric flow past the Alps has recently been considered with great interest as a relevant example of interaction of a geophysical fluid with an isolated, steep mountain range.

It therefore seems important to summarize the available information on the subject. This is in fact the aim of the following review.

Work produced in the past with explicit reference to the formation of pressure Lows near the Alps is analysed in Chapters 2,3 and 4 .

The last two (hapters are devoted to an examination of the very basic foundations of the theory of geophysical flow around obstacles (which lead to suggestions about the interpretation of some features 


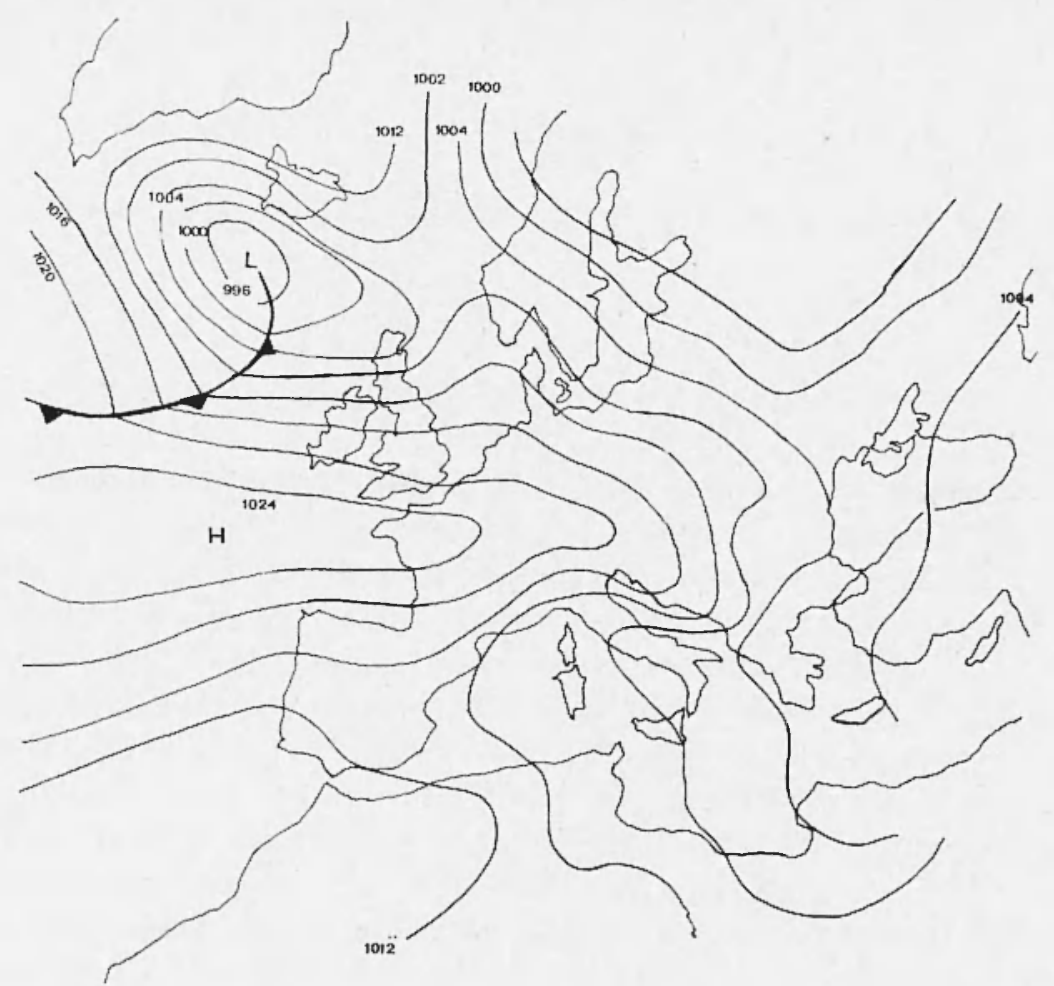

Fig. 1.1 - Pressure field at the ground (06 GMT April 19, 1967). The cold front is on the Atlantic Occan.

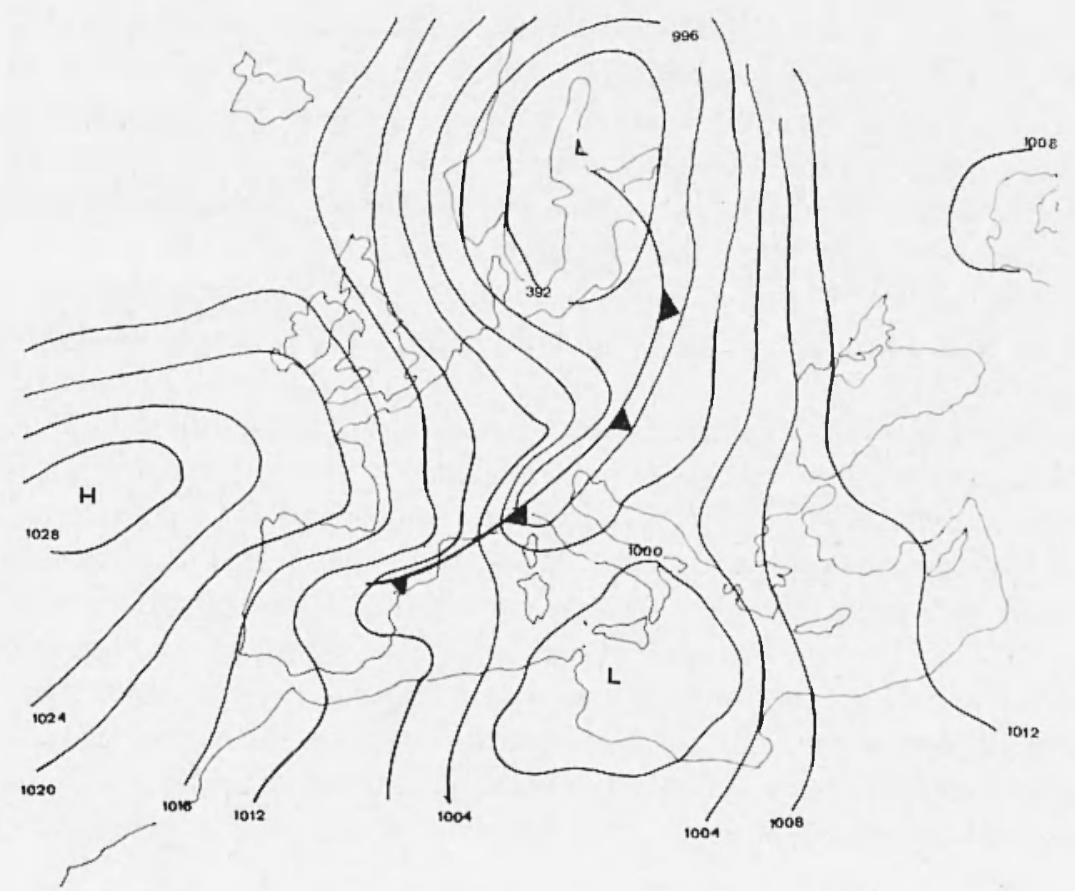

Fig. 1.2 - Pressure field at the ground (18 GMT April 21, 1967).

The cold front begins to interact with the Alps. 


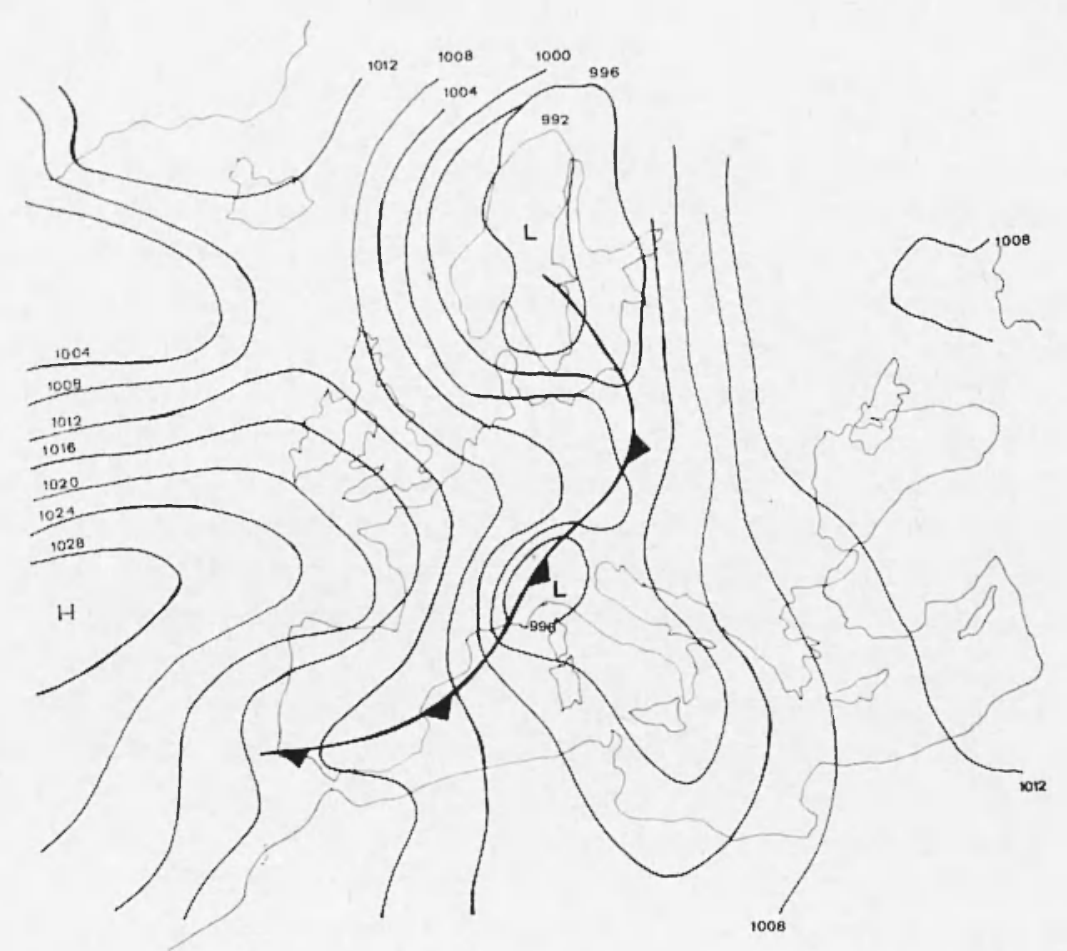

Fig. 1.3 - Pressure field at the ground (00 GMT April 22, 1967). A local Low has formed.

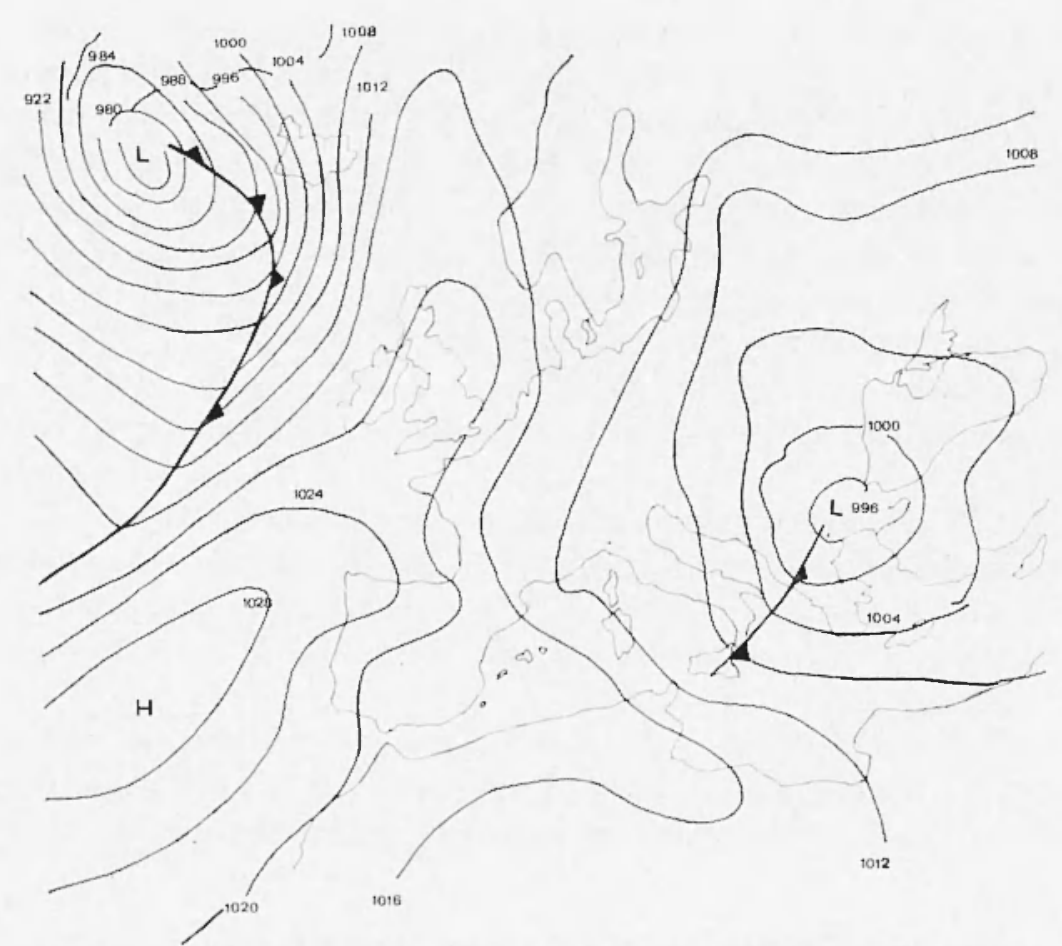

Fig. 1.4 - Pressure field at the ground (18 G.MT April 23, 1967). The depression moves eastward. 
of the baric field around the $\mathrm{Al}_{\mathrm{p}}$ ) (Chapter 5 ) and to some tentative conclusions (Chapter 6).

\subsection{FARLY IDEAS ABOUT CYCLOGENESIS}

Before the Second World War only ground-based observations were available. The most impressive aspect of the rlevelopment of local Jows as shown in surface analysis is the lowering of the pressure downwind of the $A l p s$ long before the arrival of any signal in the thermal field at ground level (see agrain Fig. 1.1 to 1.t).

Tn other words: at stations located in the lee of the Alps the pressure starts decreasing hours before the cold front crosses the mountain barier.

In terms of atmospheric dynamies, the pressure evolution at ground level is determined by the integral along the vertical of the divergence of the velocity field (tendency equation).

The lack of any signal in the thermal field at ground level therefore implies that it is a change in the divergence pattern aloft that causes the lowering of pressure downstream of the Alps.

This very basio iclea seems in fact to have appeared early in the literature: in 1920 H. von Ficker (14) expressed the concept that the vertical balance, typical of the frontal region, between rivergence in the upper layers (what he called "secondary pressure waves") and convergence in the lower layers ("primary pressure waves") is disrupted by mountains. If the blocking action of the barrier is supposed to extend only to the lower cold layers, while the upper, diverging flow can overcome the barrier without substantial retardation or deformation, an eflect of anticipated (with respect to the cold air advection) lowering of pressure downwind of the mountains is to be expecterl.

The morlel is certainly a little oversimplified. The theory of rotating fluids dictates a blocking extencled to the whole depth of the fluid for the homogeneous, incompressible flow (Proudman-Taylor theorem). The behavior of stratified fluids in this respect is still not clear (see for example (2)) but it certainly does not allow the rastic "differential blocking" postulated by Ficker.

A most direct approach to the problem would be that of estimating the rivergence in the different layers from experimental data. In fact the literature records at least one claim, for example that made by $\mathrm{E}$. Dinies $\left({ }^{10}\right)$, of having deduced from experimental data the pre- 
sence of a positive divergence pattern in the upper atmospheric layers in correspondence with a strong cyclogenetic depression. Unfortunately more recent work on the reduction of meteorological rlata (Dines' paper was published in 1938) has shown that a direct evaluation of divergence is not feasible, for practical reasons, in the proximity of mountains.

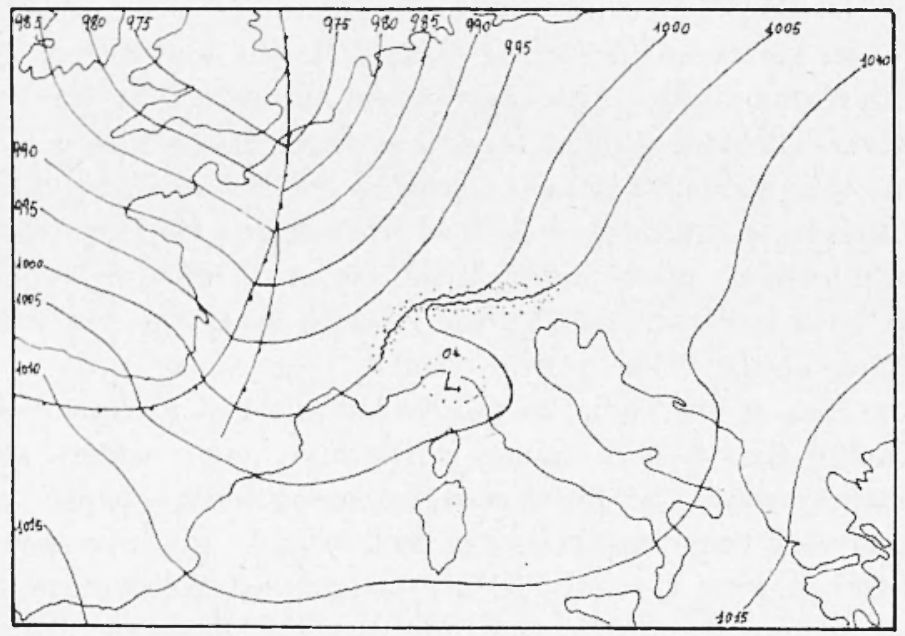

Fig. 2.1 - The sea-level chart, January 11, 1958, 00 00 GurT. Over Alps may be seen an orographic pressure ridge. Further up-stream there is a small cyclone. The cold front is still the continent (GruRCIK 1960) $\left({ }^{15}\right.$ ).

The question of differential blocking is therefore still open and of considerable interest particularly in view of recent developments (to be discusserl in Chapter 4).

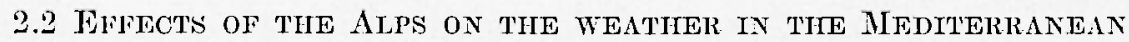

In the years immediately following the Second World War continuous improvement of the meteorological network stimulated the study of "life cycle" of the major perturbations in the Mediterranean.

In $19.18 \mathrm{M}$. Bossolaseo (1) tried to classify the evolutive properties of the depressions formed in the Ligurian Sea (that he, again in terms of quasi-geostrophic dynamics, called cyclones). Then followed 
a study $\left(^{2}\right)$ of the tracks and the energeties of specific perturbations. Similar classifications of the frequency of "cyclone formation" etc. were marle by T. A. Gleeson (16, 17).

The main result of these studies was an improved qualitative understanding of the phenomenology of interaction of large-scale atmospheric flows with the Alps. Statistical work based on an ever increasing volume of data continued for years.

The probability of formation of depressions near the Alps in the different seasons was estimated by ML. Urbani $(35,36)$ who in 1956-5 7 analysed about ten years' meteorological data (from 1946 to 1955). Urbani's statistics showed a strong predominance of the frequency of formation of depressions in the Ligurian Sea during the winter, while during the summer other regions near the Alps (Po Valley, Northern Adriatic) tend to be subject to the action of local Lows. $\Lambda$ s we shall see later (in Chapter 3 ) these results were confirmed by further climatological work.

It should however be kept in mind that this kind of statistical work is often based on "criteria of selection" of events belonging to the analysed ensemble, that are more conventional than they are physically significant. In fact the number of events quoted in the literature of the statistical properties of atmospheric flows near the Alps shows that "cyclogenesis" is intended to signify "formation of a rolative Lıow". As we observed in the introduction the two things are equivalent only in quasi-geostrophic dynamics. Since flows in the region immediately surrounding the $\Lambda$ lps are, presumably, strongly affected by inertial effects, the observed ambiguity learls to heterogeneous ensembles. We shall return to this problem in the following Chapters.

At the end of the fifties, while the studies on the weather in the Mediterranean continued (see for example ( $\left.{ }^{33}\right)$ ) the first contributions to the problem in question made by researcher's in Eastern Europe appeared in the literature $(15,17)$. Particularly interesting (and clear) is Gburcik's attitude to the problem $\left({ }^{15}\right)$ :

"The fact that cyclones occur more frequently over the Gulf of Genoa than in surrounding regions suggests that the cyclogenesis must be induced by the influence of the ground.

Two kinds of influence may be expected:

1) the thermal influence of the warm sea surface on the cold air mass, 
2) the mechanical influence of some obstacle on the air stream ... it is obvious that the thermal effect of the sea-surface may appear only when the coll air-mass comes over the sea, but in the synoptic charts a cyclonic circulation over the Gulf of Genoa can often be seen while the front is still progressing over the eontinent. Such a situation is shown in Fig. 2.1.

The thermal eflect on the sea-surface has here apparently little influence and the only possibility that remains is the influence of the mountains".

Inere too, the lows in the pressure field are interpreted as indicative of a closed circulation and a statistical predominance of the Gulf of Genoa as a "cyclogenetic region" is assumed.

In the meantime, while all the eited work on woather in the western Iediterranean was being produced, the intensive study of

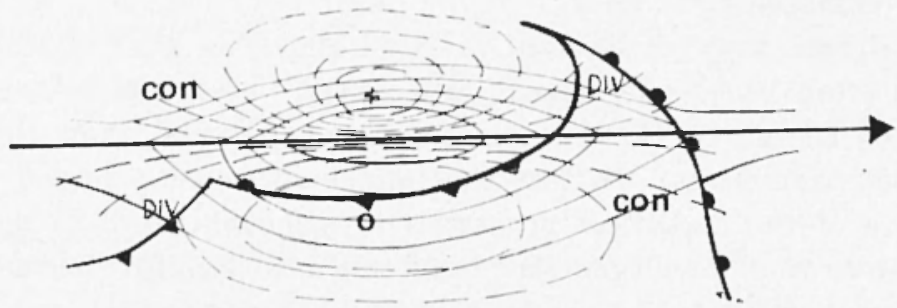

Figr. 2.2 - Schematic representation of surface fronts, as well as of vorticity distribution (dashed) and of divergence at the $300 \mathrm{mb}$ level in the vieinity of a jet maximum (isotachs $=$ full lines) (REITER 1963) ${ }^{(29)}$ ).

atmospheric flows caused the appearance of new phenomenological concepts.

A new way of describing tropospheric flows and their dynamics, alternative to the frontal theory, began to take place: the jetstreammeteorology. The basic idea is that cyclogenetic activity at ground level is associated essentially with strong jet-like flows in the upper troposphere. Fig. 2.2, reproduced from Reiter's elassical book (29) about the Jet-Stream, illustrates the relative distribution of the various fields involved in the process. In the case of a strong northerly jet a cyclone and an anticyclone typically develop on the two sides of the upper velocity maximum. In important consequence of this approach is that if the upper air jet is deflected a "secondany" cvologenesis can take place near its new location. In fact: "Especially 
during winter two cyclogenetically active belts are clearly indicated, one of them originating on the East coast of Asia and with cyclonic curvature, merging into the Aleutian Isow; the other extending from the lee of the Rocky Mountains into the Norwegian Sea. Thus, both bands follow the mean jet-stream position. The region of the Genoa cyclone which forms under the influence of a north-westerly jetstream is especially well marker in these statistical distributions". (See again (29) pages 368-369).

These concepts, even though they are inconclusive, are important. More will be sair about later developments in section 4.1 etc.

\subsection{THE "IAEE-CY" PROGRAM}

In 1961 the first systematic investigation of the problem in question was started in a joint NATO, CNR, ITAV program. The program was given the conventional name of "Lee-Cy" and lasterl up to 1964 (even though the results of data-analysis continued to be published for several years afterwar(s).

The final results were mainly statistical correlations among long time-series of meteorological data and detailed synoptic and mesosynoptic analysis of specific events. In fact, most of the experimental material available today was produced during the intensive ratacollection performed by researchers involved in the program.

We shall only comment on the most significant contributions the rearler interester in further details should refer to the papers $(5,7,25,37)$ cited in the bibliography.

It is worth mentioning here the criterion of selection of the events that is basic to all the work performer throughout the "Iuee-Cy" program: "there is a cyclogenesis whenever the circulation over northern Ttaly, i.e. over the Po Valley, the Ligurian Sea and particularly the Genoa Gulf, develops in such a way that on the sea level pressure charts, with isobars traced every one millibar, at least one cloesd isobar appears in the trough usually aftecting the area, and the observed or estimated pressure gradient is at least $\left.1 \mathrm{mb} / 100 \mathrm{~km} "{ }^{5}\right)$.

As we shall show later the pressure pattern is connected in a rather indirect way to the flow pattern in the proximity of obstacles generating strong non-geostrophic seconctary flows. In this sense the appearance of closed isobars at ground level is not direct evidence of the presence of eyclonic vorticity. (The lack of clirect 
number of cyclogenesis events

(a)

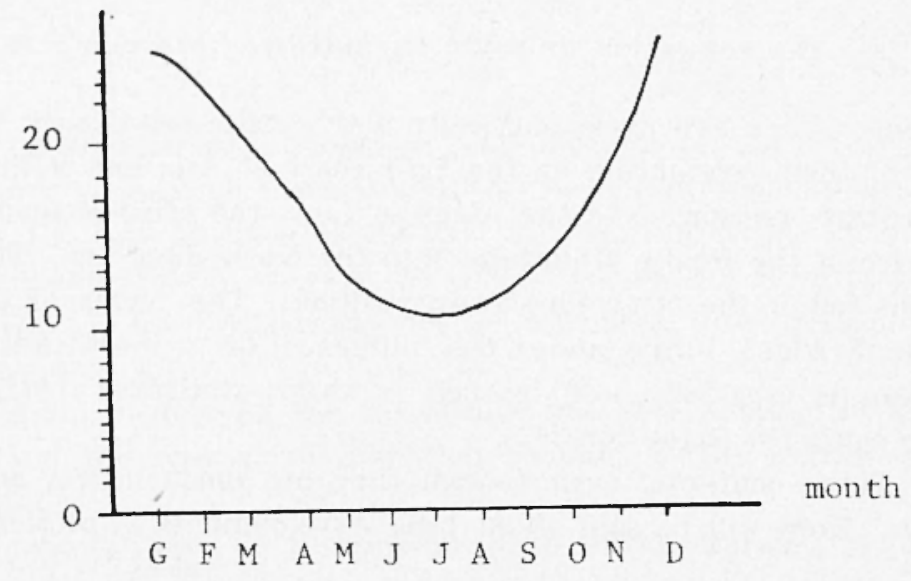

number of cyclogenesis events

(b)

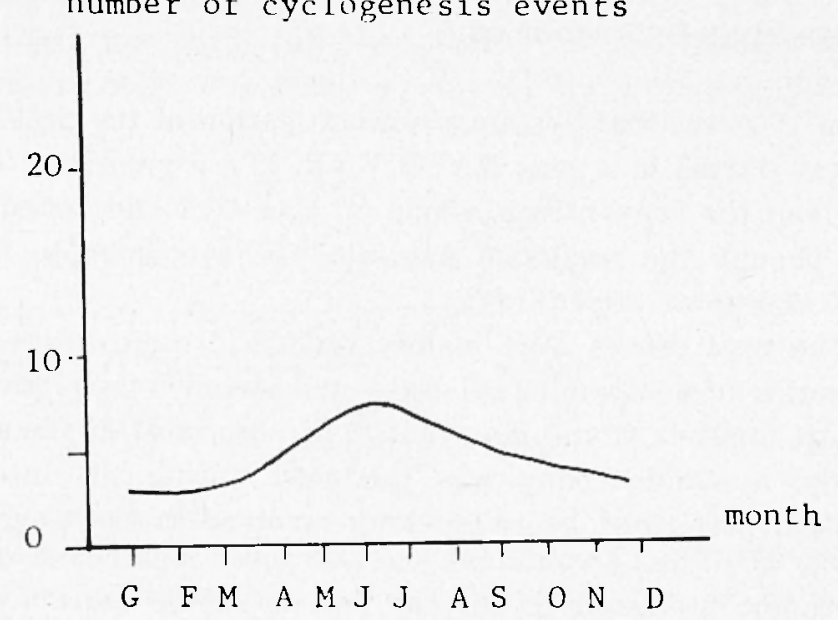

number of cyclogenesis events

(c)

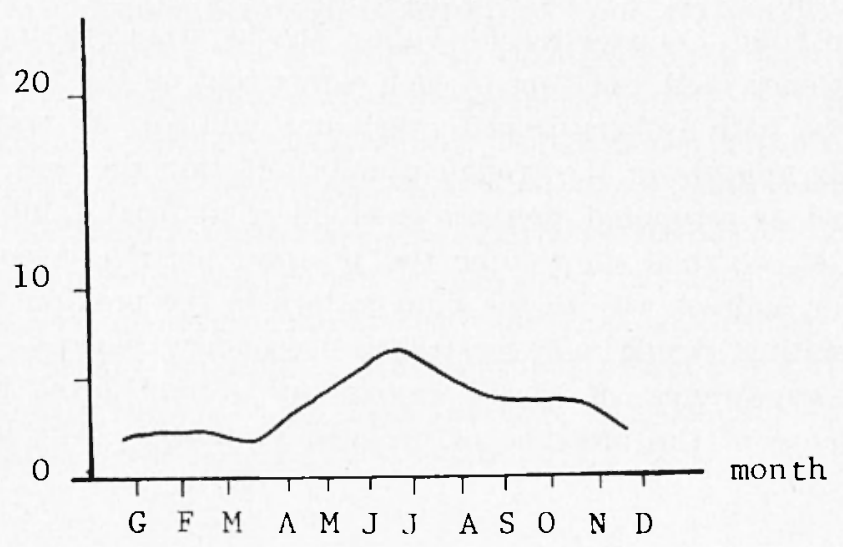

Fig. 3.1 - Number of eyelogenesis events per month

a) in the Ligurian Sea (b) in the Po Valley

b) in the Northern Adriatic Sea (Montalo et al. 1967)(25). 


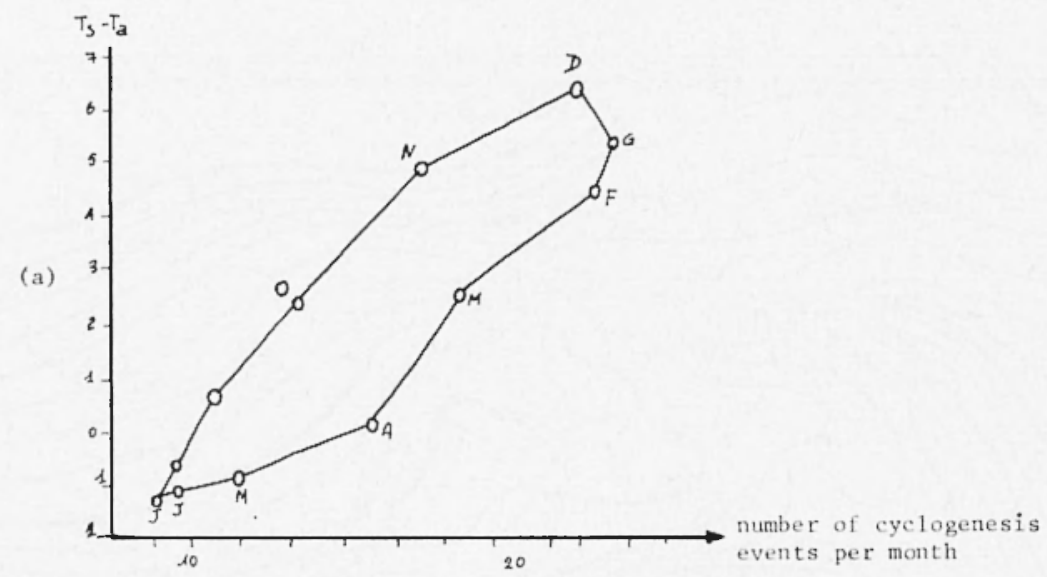

(b)

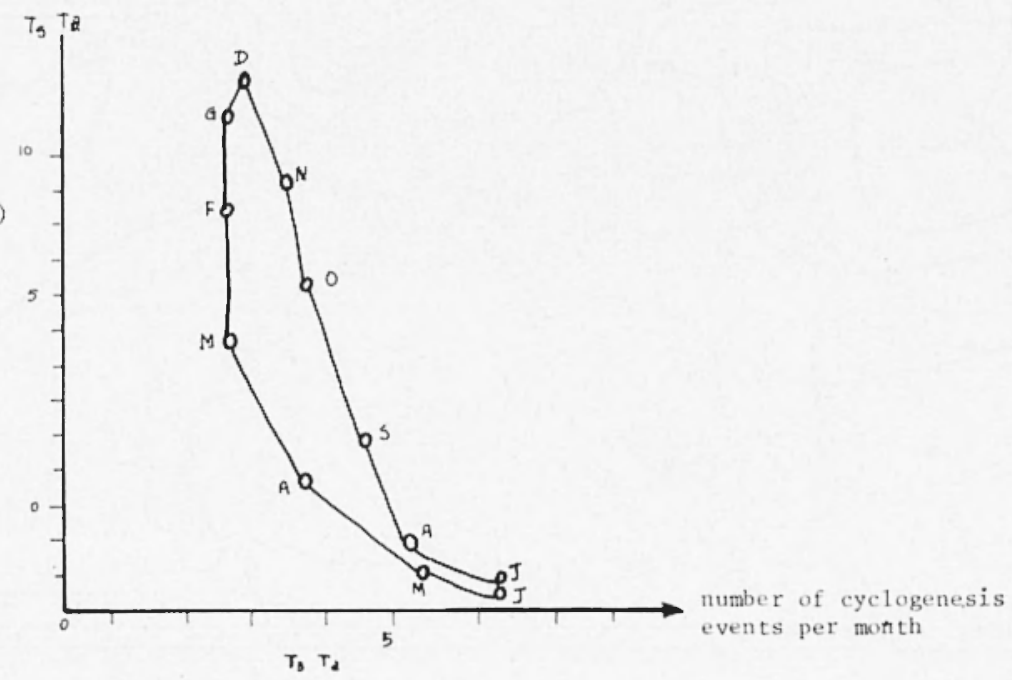

(c)

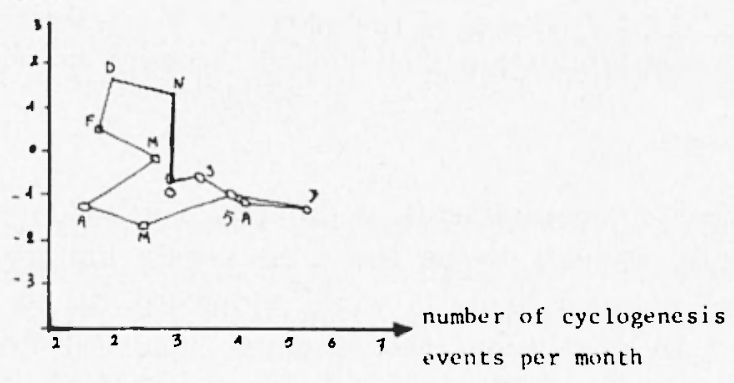

Fig. 3.2 - Number of eyclogenesis events per month against temperature difference between sea (T) and air (T), (a) in the ligurian Sea (b) in the Po Valley (c) in the Northern Adriatic Sea. (Mostatro et al, 1968) (24). 


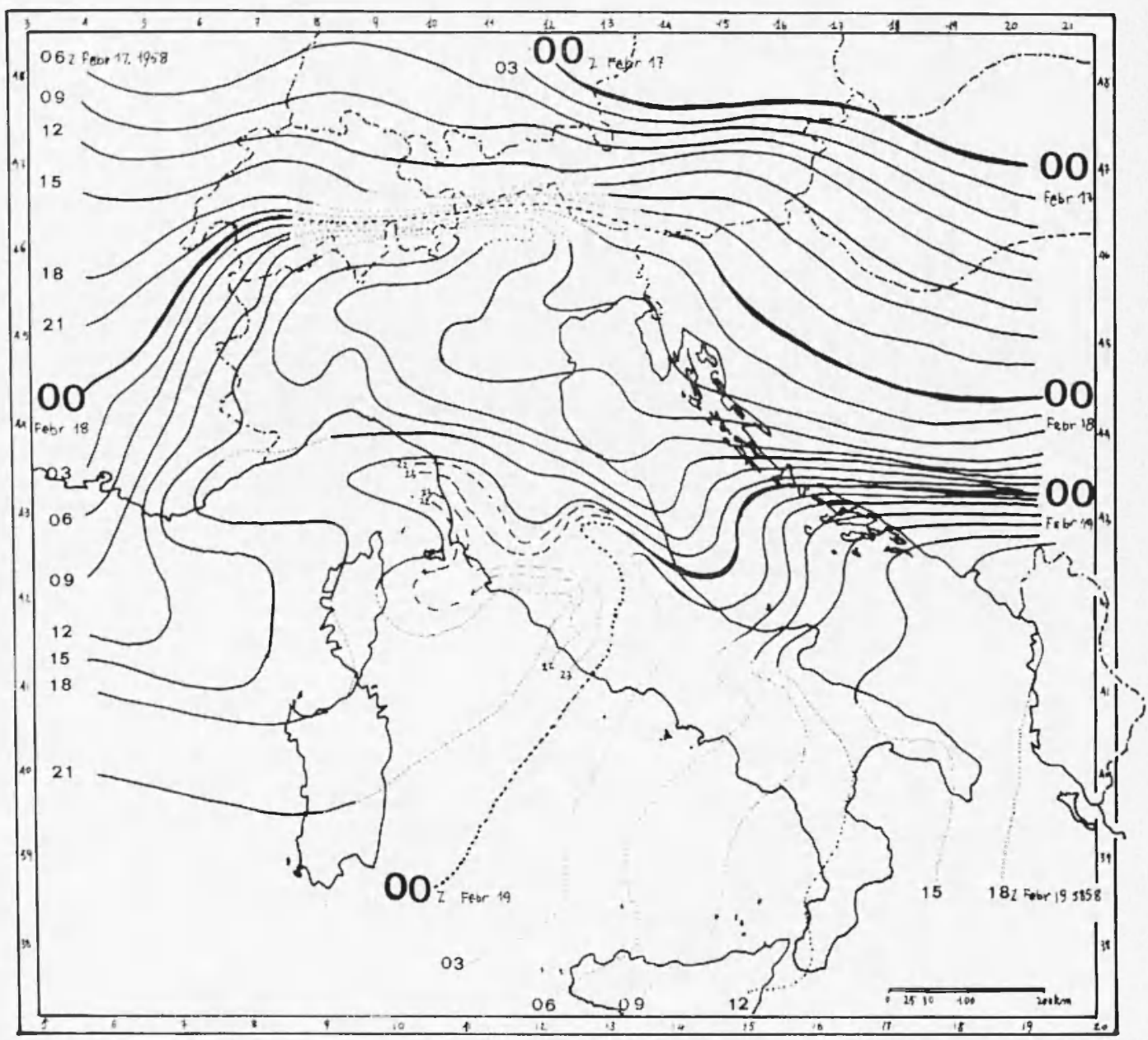

Fig. 3.3 - Isocrones of the main cold front; solid line: abrupt decrease in temperature; dashed line: gradual decrease in temperature (VIscoser et al. 1965$)\left({ }^{37}\right)$.

velocity measurements at different vertical levels near the mountains really appears to be the most severe limitation to both statistical and detailed analytic work performed up to now!, see Chapter 5).

In eonclusion, the ensemble analysed during the development of the "Lee-cy" program is most probably a composite of events of different physical nature: strong baroclinic deepenings, orographic and thermal Lows. 


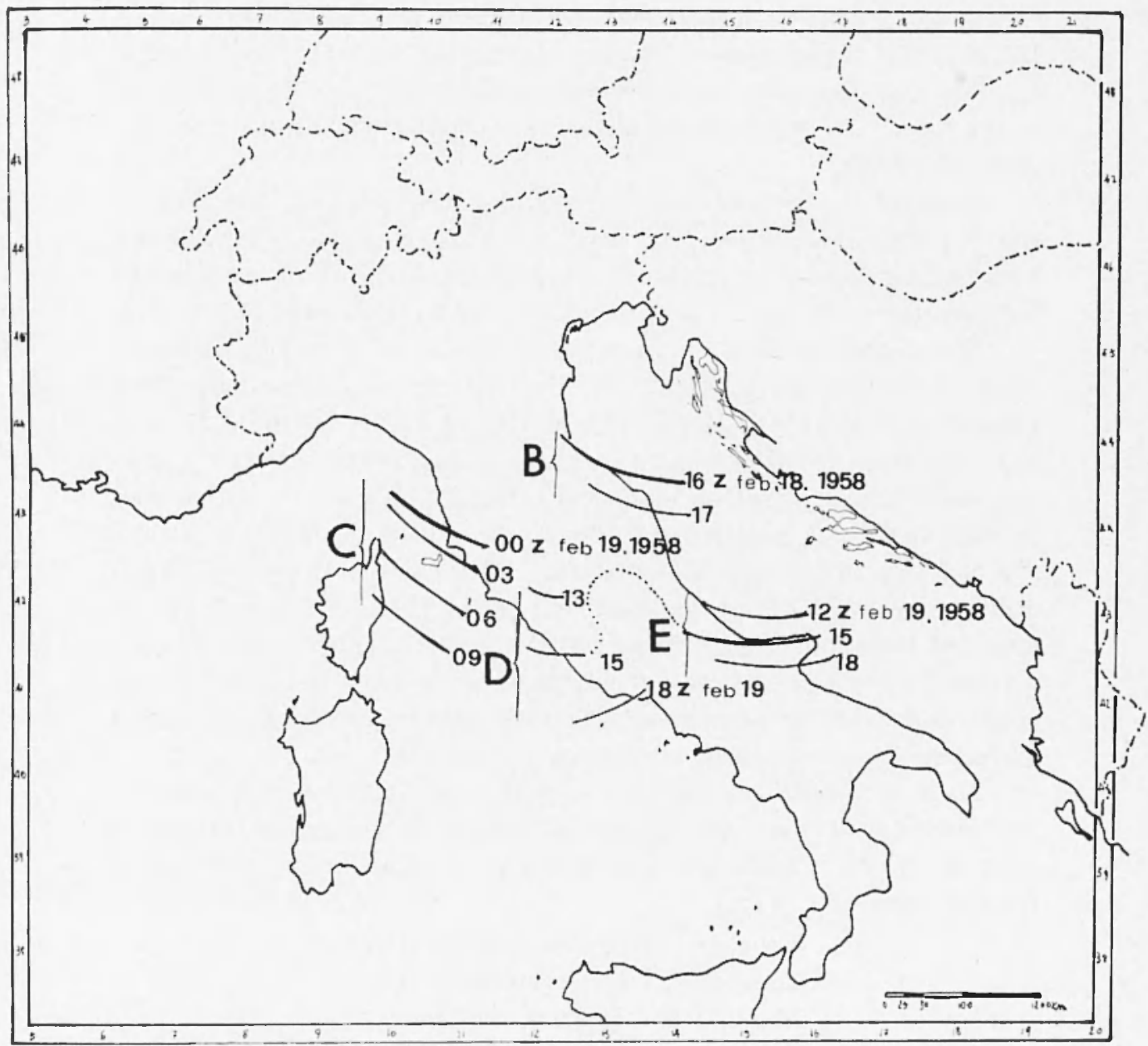

Fig. 3.4 - Isocrones of the secondary cold fronts; solid line: abrupt decrease in temperature; dashed line: gradual decrease in temperature (Viscosti et al. 1965) $\left({ }^{37}\right)$.

Even if subject to the technical limitations discussed, a very interesting contribution is the elimatological analysis by M. Montalto et al. $\left({ }^{25}\right)$, of ten years' (1952-61) data of pressure and temperature at ground level.

The seasonal distribution of events is well illustrated by the graphs of variation of the number of ryclogenesis events per month in three different climatic rogions south of the Mlps shown in Fig. 3.1. 
It can easily be seen that the formation of pressure-lows in the ligurian Sea is particularly frequent cluring the winter. This confirms the fact that the basic input for the phenomenon is to be looked for in the flow pattern associated with the arrival of cold fronts from the Atlantic Ocean.

Some of the parameters that modulate the seasonal variation of the "Cyclogenesis density function" are backed up by its correlation with climatologically significant parameters such as the difference between the temperature of the air and the sea illustrated in Fig. 3.2.

The degree of correlation is rather impressive. It is not, however, clear which physical processes are involved. For example, the claim that the strong dependence of the number of events on the difference in temperature between air and ground is indicative of thermodynamic processes connected with the vertical exchange of heat is questionable. In fact the input function, i.e. the frequency of incoming fronts, is also subject to seasonal modulation. As a result, the temperature difference could, at least partially, be an indicator of seasonal modulation of the input function and not of a real, specific thermodynamic process. It would not be difficult to remove such ambiguity if the same analysis were performed with the insertion of "normalization" in respect to the number of incoming cold fronts.

More conventional, and therefore less original, contributions are the analyses of particular events produced in the same "Lee-Cy" program (5, 37). The baric and thermal configurations were traced for the periods:

February 17 to February 19, 1958

December 5 to December 7, 1971

March 4 to March $6,1964$.

All the events reveal the classical evolution partially described in the introduction a frontal north-westerly flow, associated with a strong trough, interacts with the Alpine barrier, giving rise to a local cyclonic formation.

It should be noted that the process analysed here is a real cyclogenesis on a space-scale covering all the western Mediterranean and not a simple formation of a depression in the baric field as in most of the events considered in the climatological analysis.

In the way of detailed analysis the obvious tendency towards small scale description of the meteorological fields, particularly near the Alps, is counteracted by the difficulty of filtering "noise" in order 
to keep track of definite mesoscale signals. The problem is well illustrated by the map of isocrones of the passage of the cold front at ground level $\left({ }^{37}\right)$ shown in Figs. 3.3-3.4.

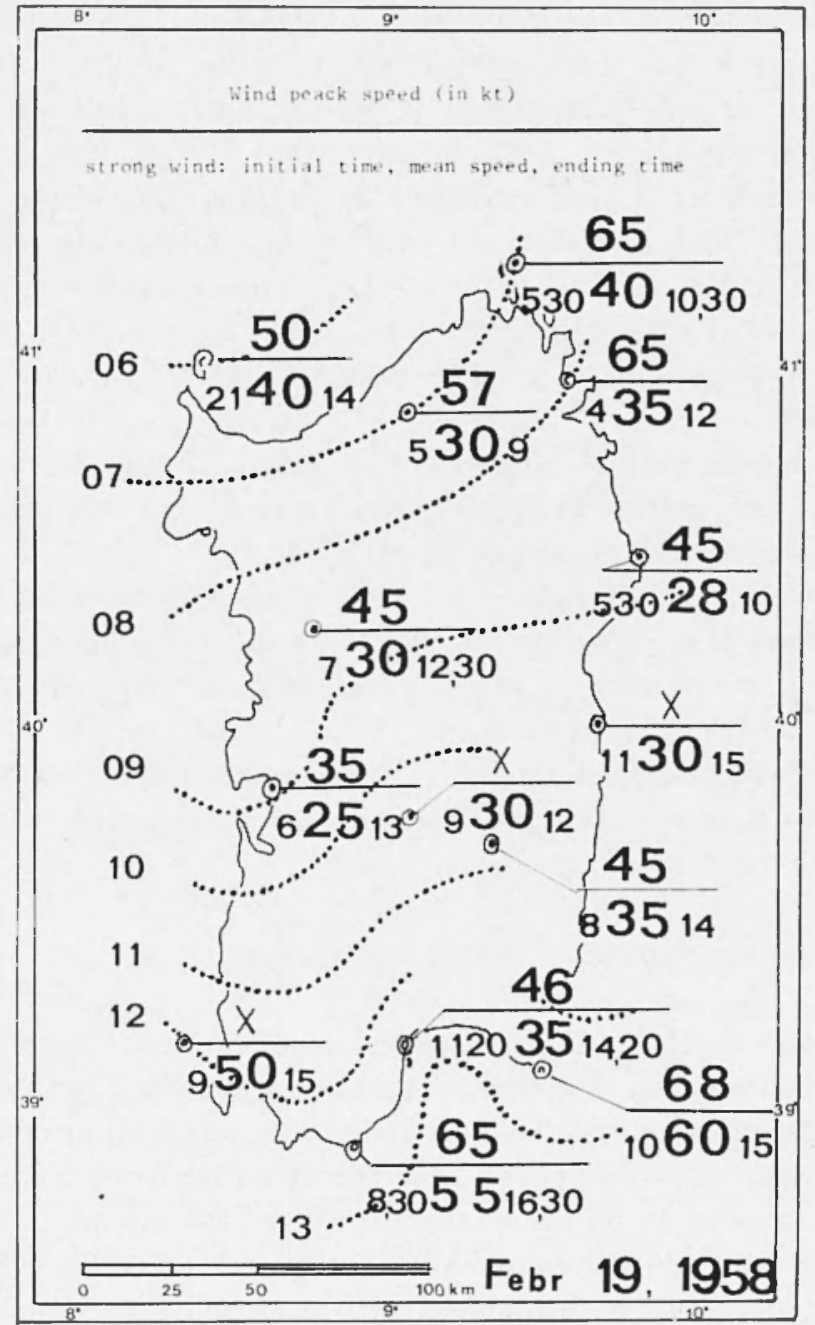

Fig. 3.5 - Isocrones of the wind peak over Sardinia (Visconte et al, 1965) $\left({ }^{37}\right)$.

As can easily be seen the thermal "signal" is very intense and spatially coherent as long as the front is on the Atlantic: Ocean, but as soon as the cold air approaches the western Iediterranean the 
space-coherence is lost, while the intensity remains almost unchangrerl.

As a result it is possible to keep track of the cold air's arrival at fixer locations, but the front can no longer be locater precisely. As an illustration of the "succession of impulses" associated with the "cold outbreak" in the Ligurian Sea, we give, in Fig. 3.5, the map" of isocrones of cold air passage at ground level over Sardinia (again taken from $\left({ }^{37}\right)$ ).

The tendency of the cold front to fragment into "cold air drops" is indicative of modulation on small space scales and, possibly, of separation of the flow with the cold air streaming towards Sardinia.

It would be interesting to know whether the same small scale modulation is present in weaker events of simple formation of baric depressions.

The loss of space coherence also makes it rlifficult to interpret the mesoscale pressure and the temperature fields, as is clearly shown by the retailed analysis griven in Fig. 3.6.

In conclusion, it seems clear that more sophisticater techniques of data-reduction (filtering of eflects of altitule, modulation from local heat source etc...) are required in order to learn more from detailed analysis.

Again the interested realer is invited to refer to references $(5-725,37$ ) as a source of many more interesting details of the problem in question.

\subsection{THE SEMI-EMPIRICAL PREDICTION MODELS}

In $1965 \mathrm{D}$. R. Rarlinovic $\left.{ }^{28}\right)$ produced the first prediction scheme for cyclogenesis near the Alps. The basic hypothesis is that the main large scale effect of the Alpine barrier is a retarlation of the arlvection pattern. It is supposed that the Atlantic front is blocked and the cold air piles up on the wind ward side of the mountain chain until maximum cyclonic development takes place. The blocking of the front is thought to be associated with a strong intensification of the horizontal thermal gradient on the windward side of the Alps and therefore, in geostrophic approximation, with a thermal wind flowing along the barrier. The arch-like shape of the mountain chain causes the seconclary flow to possess a strong eyclonic vorticity. An approximate prediction of the baric field can be performer by means of a graphical reconstruction of the advected thermal field deformed by 


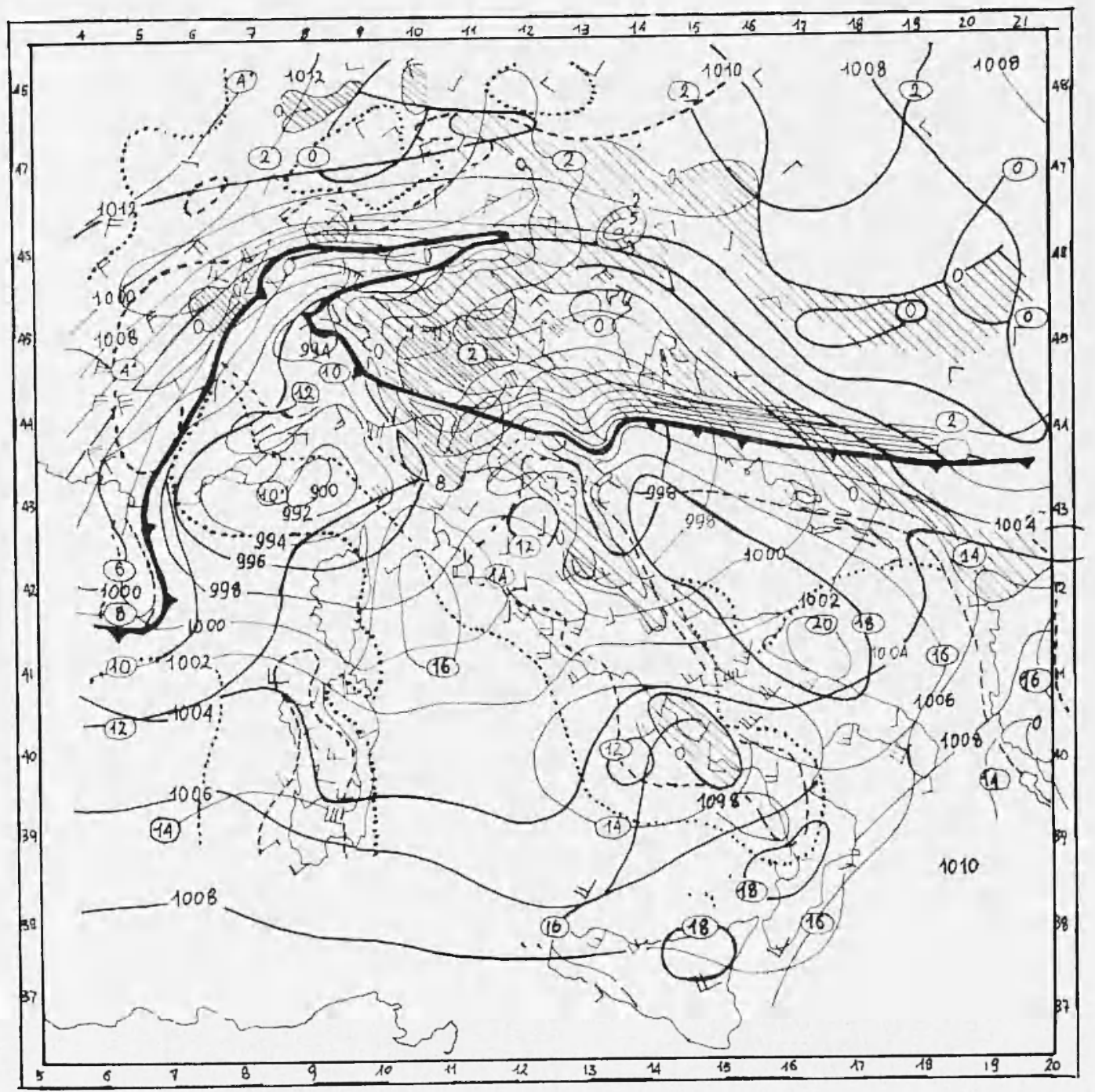

Fig. 3.6 - Detailed analysis at $1200 \mathrm{Z}$ of February 18, 1958 (VIsconti et al. 1965) ${ }^{(37}$ ).

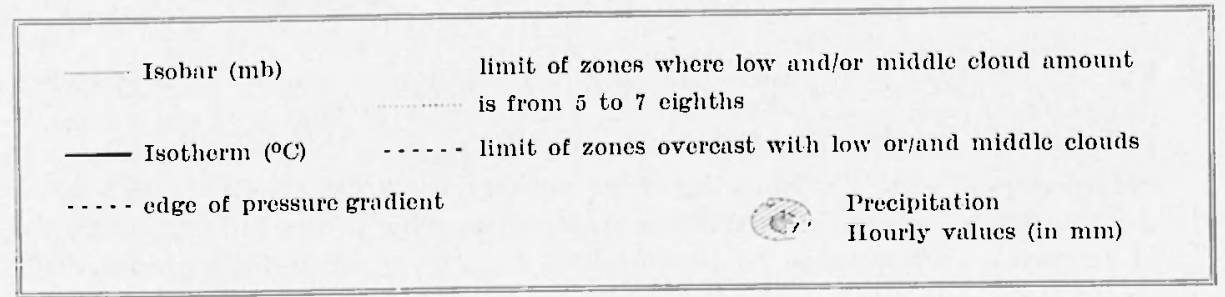


the "retardation" caused by the Alps. An example of the procedure is given in Fig. 3.T.

Also in 1965 the old problem of differential blocking was considered by Sheragr ( $\left.{ }^{32}\right)$. Sheragr's morlel is essentially a more sophisticated version of the old theory of "primary and secondary pressure waves" (see Section 2.1, $\left({ }^{14}\right)$ ). The convergence-divergence balance that is typical of frontal regions is supposed to be disrupted since the blocking action of the mountains is exerted only on the lower layers, while the divergence pattern aloft is advected downstream without any essential modification. The presence of divergent flow aloft causes a decrease in pressure on the lee side of the Alps (Tendency equation). The distortion along the vertical of the flow pattern is certainly an important feature and plays a predominant role in later theories about cyclogenesis (in particular Egger's numerical model $(12,13)$ to be discussed in the following Section).
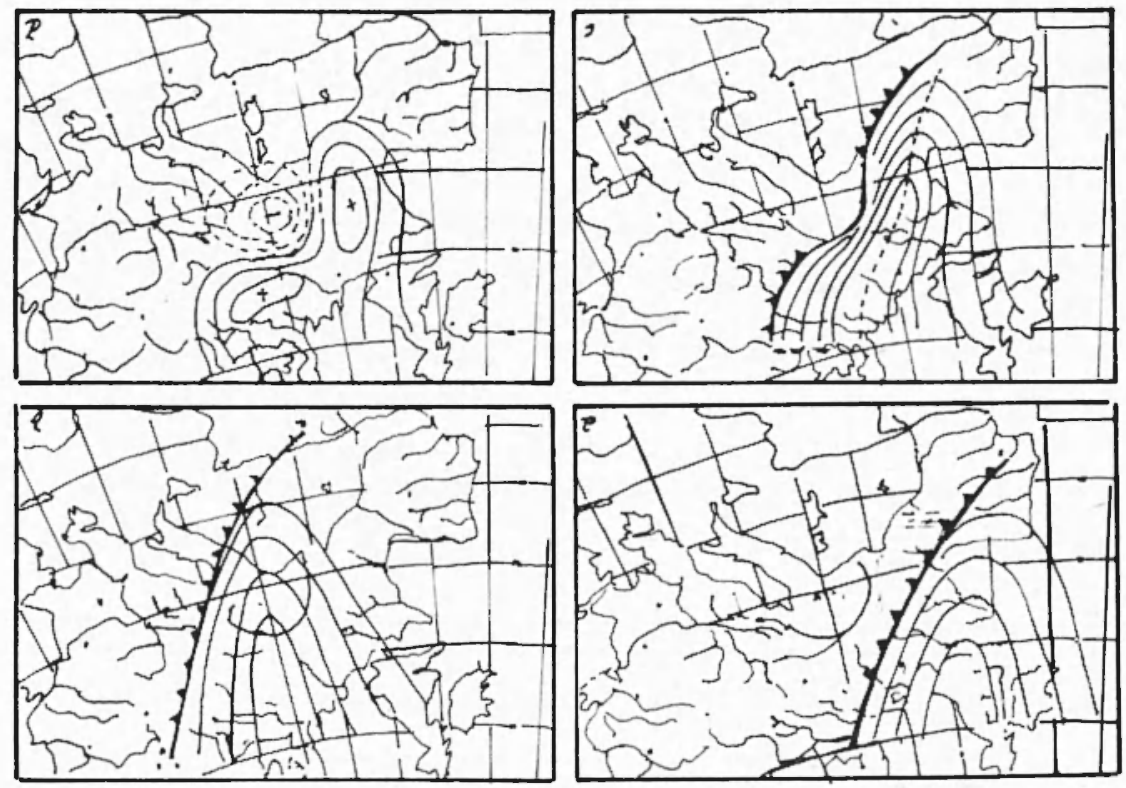

Fig. 3.7 - Schematie figures showing the orographic effect. a) Idealized thickness trough approaching the $\Delta l_{p}$ s mountain; $b$ ) The position of the thickness trough over the $A$ lps area in the idealized case when the mountain ranges do not exist; e) Showing deformation of the thickness trongh on meeting the mountain barrier of the $\Lambda l_{\text {ps; }} d$ ) Showing schemat ic distribution of vorticity correspondig to the thickess in Fig. c (RAdscovic 1965). $\left({ }^{28}\right.$ ) 


\subsection{TIIE FIRST YUMERICAL MODEL.}

During the years 1970-72 J. Egger published the results of his work on the incorporation of steep mountains in numerical forecasting. The problem of flow past the Alps was chosen as a specific test for his technique.

Egger's numerical soheme $(12,13)$ is an improved version of the one worked out by W. Elelman for a study of the generation of frontal discontinuities in the atmosphere: primitive equations are integrated in a zonal channel with a mesh-width of $350 \mathrm{~km}$ and five $\sigma$-levels along the vertical.

What is new in Egrger"s work is the fact that the action of the Alps on the flow is simulated by the introduction of complete blockingr conditions in the two lowest $\sigma$-levels along a contour approximately representing the shape of the mountain barrier.

The fluid is therefore forced to flow "around" the barrier in the lowest blocked levels, while flowing undisturbed "over" the barrier in the remaining part of the simulated troposphere.

The initial condition is theoretical and it is characterized by a deep Low superimposed on a general westerly flow. Iterative integration of primitive equaticns shows that, after an initial shock due to the artificial initial condition, there is a tendency for pressure to decrease regularly on the windwarl sirle of the Alps. An aceurate analysis of time-variation of the different terms involved in the tendency equation shows that the lowering of pressure is essentially due to the divergence in the upper layers caused by the pre-frontal advection of warm air in the warm sector of the initial large scale Low.

Typical configurations of the barie and thermal fields in Egrger's experiments are shown in Figs. 4.1 and 4.2 .

Successive numerical experiments brought Egger to the followingr ronclusions:

(i) baroclinity of the initial state is essential for the development of a cyclogenesis after the initial shock.

(ii) the Pyrenees and the mountains of Dalmatia influence particularly the latest stages of development of the secondary cyclone.

Cnfortumately the lack of computer time seriously limits Eggrer's experiments. A mesh width of $350 \mathrm{~km}$ is too coarse to permit ardequate resolution of strong sub-synoptic scale motions.

Iore work on the subject is required. 


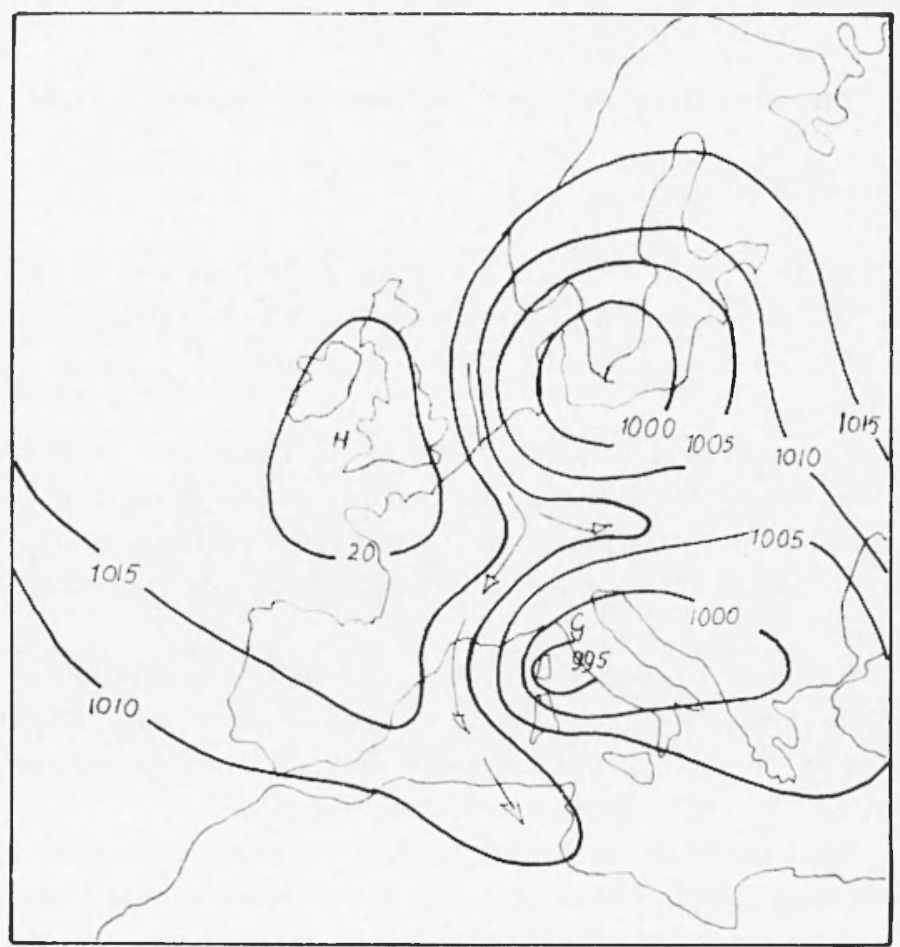

Fig. 4.1 - Surface pressure 48 hours after the initial time. (KGger 1972) $\left({ }^{13}\right)$.

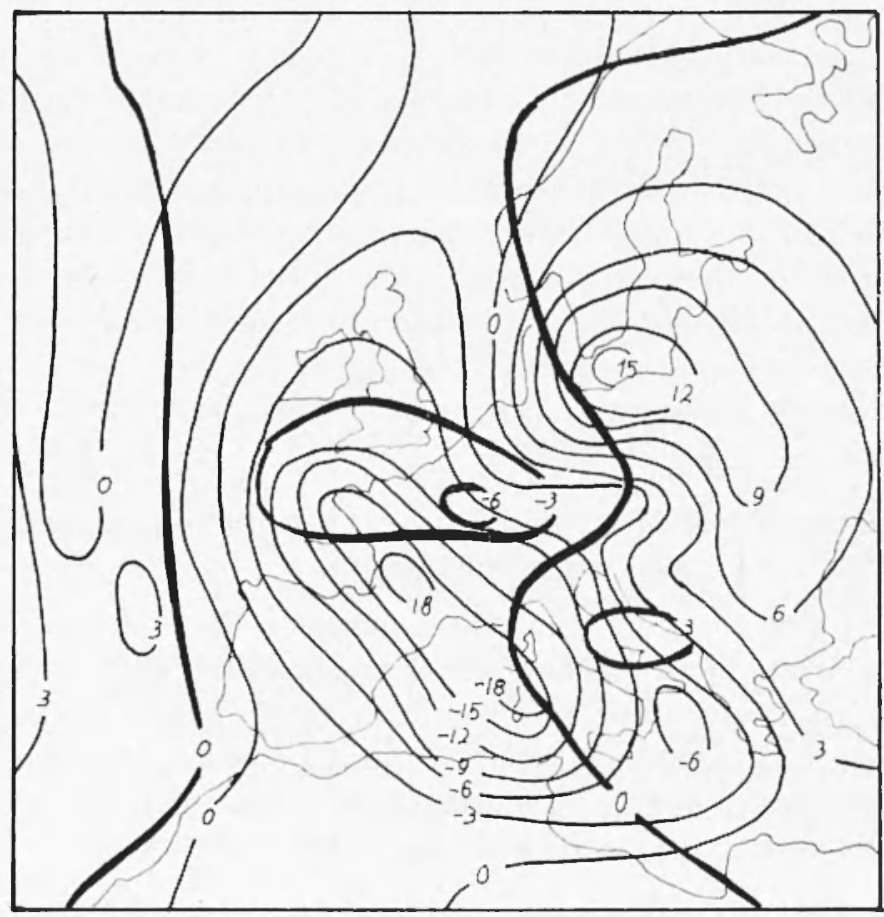

Fig. 4.2 - Deviation of the temperature $(\mathrm{o})$ ) from the initial basic distribution in $\sigma=0,92$ (full) and $\sigma==0,58$ (dashed) 48 hours after the initial time. (EGrier 1972) $\left.{ }^{(13}\right)$. 


\subsection{BAROCIJiNic DEVELOPMENT AND THE COLD JET}

We have already mentioned, in commection with Reiter's (29) work (at the end of Section 2.2) the important role of the atmospheric jets in the development of large scale cyclones.

During the last few years a complete "philosophy" of interpretation has been developed (particularly by NCAR researchers) by means of the systematic use of isoentropic analysis. It is worth resuming shat, in synthesis, is the basic picture of cyclonic development in connection with jet phenomenology. The development of finite amplitude baroclinic instability is characterized by the intrusion of stratospheric air of strong potential vorticity (tropopause folding) as shown schematically in Fig. 4.3.

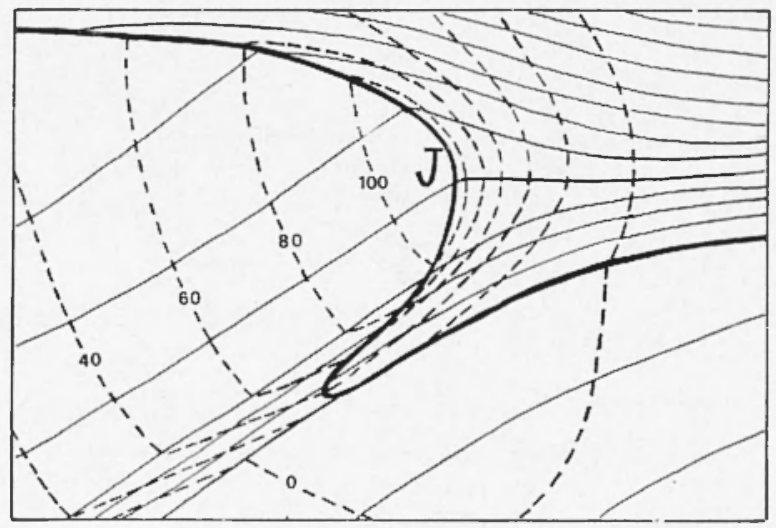

Fig. 4.3 - Tropopause folding (Danielsex 1973) $\left({ }^{8}\right)$.

Cold and dry stratospheric air flows in the form of a cold jet descending along the slopingr isoentropic surfaces (the motion is essentially adiabatic) and finally interacts with the ground as shown sohematically in Fig. 4.t.

The process of "readjustment" following the injection of the momentum excess associated with the jet, tends to give rise to a ty. p- $^{\text {- }}$ ical Low-High configuration in the baric field. The successive stages of this process are illustrated for the simple case of a barotropic fluid (as is well known the theoretical solution of this problem has been 


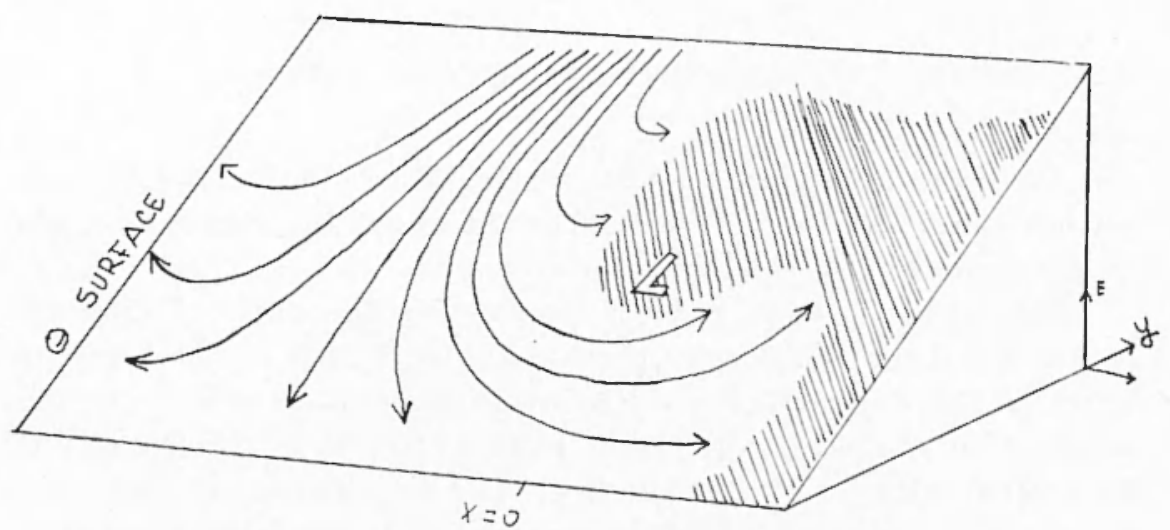

Fig. 4.4 - Streamlines on an Isoentropic Surface during Cyclogenesis (I)ANELSEX 1973$)\left({ }^{8}\right)$.
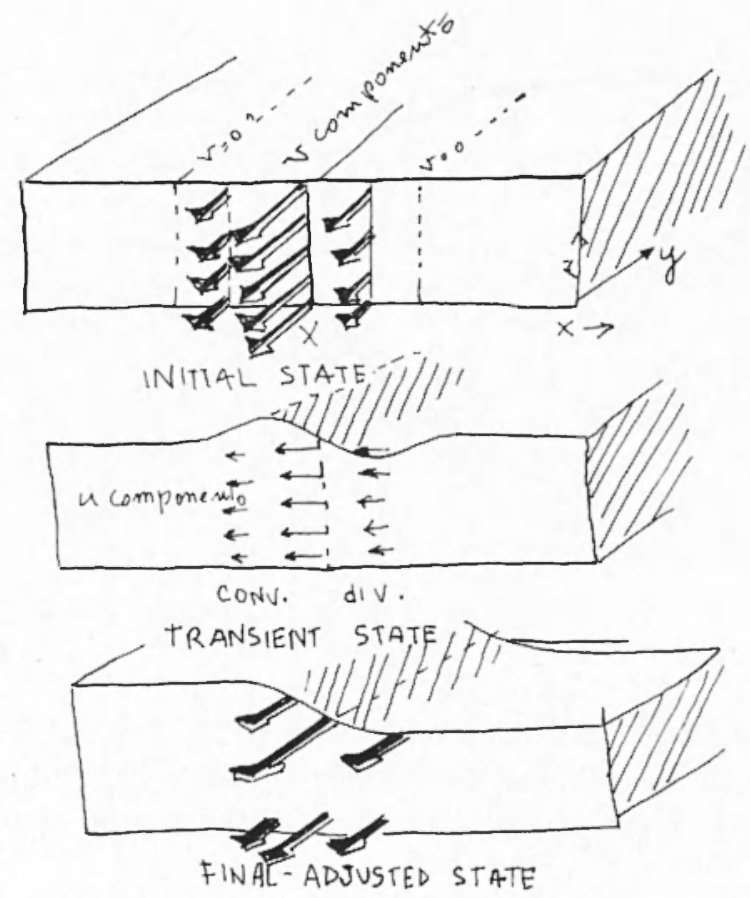

Fig. 4.5 - Pressure adjustment to Deep Jet. (Danielsen 1973) ${ }^{8}$ ).

found by C. (a. Rossby) in Fig. 4.5. The analogy with the Iow-High configuration in Fig. 4.4 is evident. 


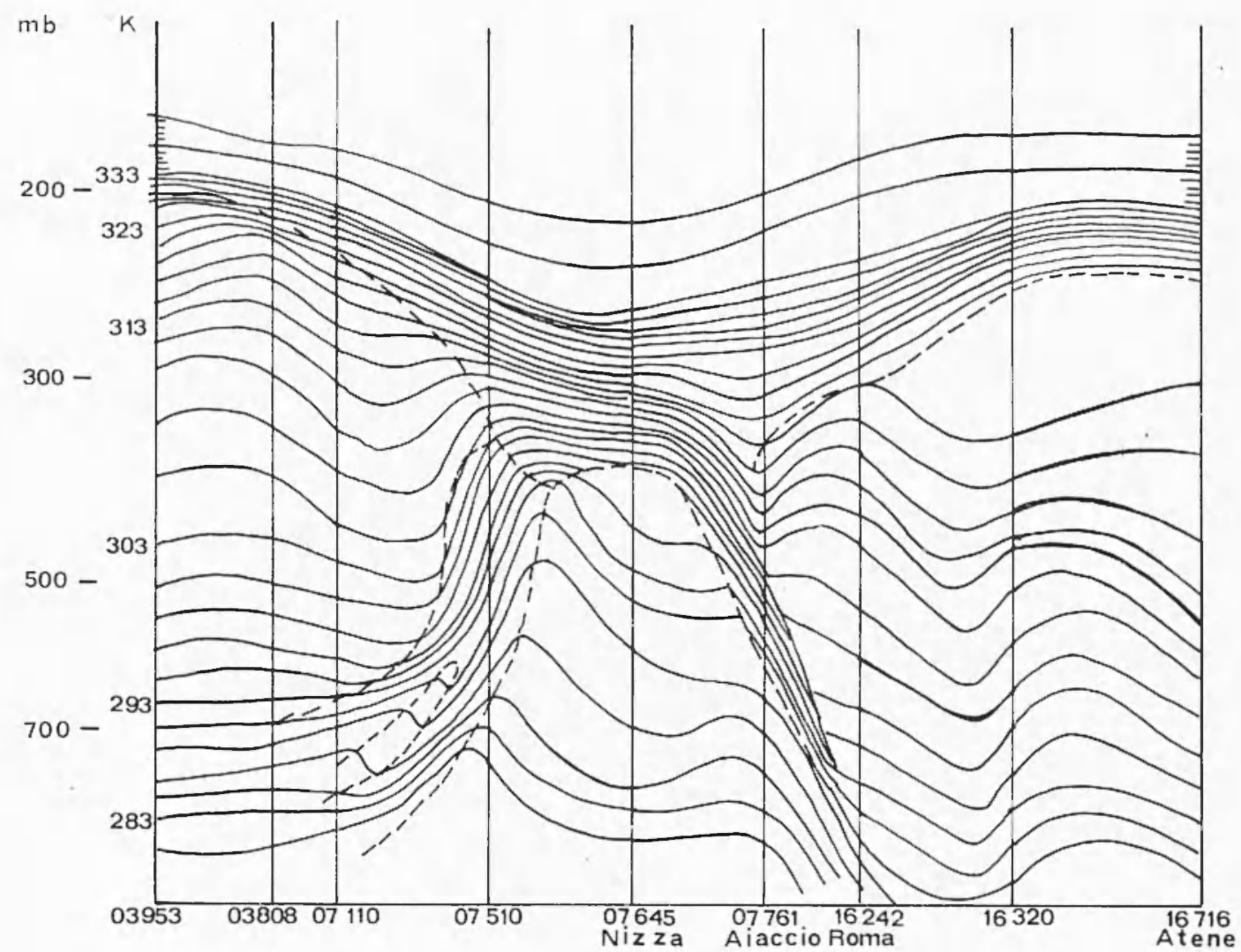

Pig. 4.6 - Vertical cross-section, + Feh. 1200 (:MIT, 1969. Isentropic surface at $2^{\circ} \mathrm{K}$ interval; (Buzzi, Rizzi 1975) $\left({ }^{3}\right)$.

The same interpretative scheme and techniques were applied by E. Ianielsen to the problem of ayologenesis near the Alps. Isomtropic and trajectory analysis of two strong events (3-5 February, 1-6 December 1969), initiated by Danielsen $\left(^{8}\right)$ and completed by A. Buzzi and R. Rizzi ${ }^{3}$ ) shows that essentially the same features of large sale cyclonic development (tropopause folding and cold jet) are present in the western Mediterranean during the generation of eyclones on the windward side of the Alps (see Figs. 4.6-1.11).

In Tanielsen's works:

"In conchusion, the evidence supports the concept of deep baroclinic instability as the primary anse of cyclogenesis in the Gulf of Genoa, but topography controls the location of the cyologenesis. In 


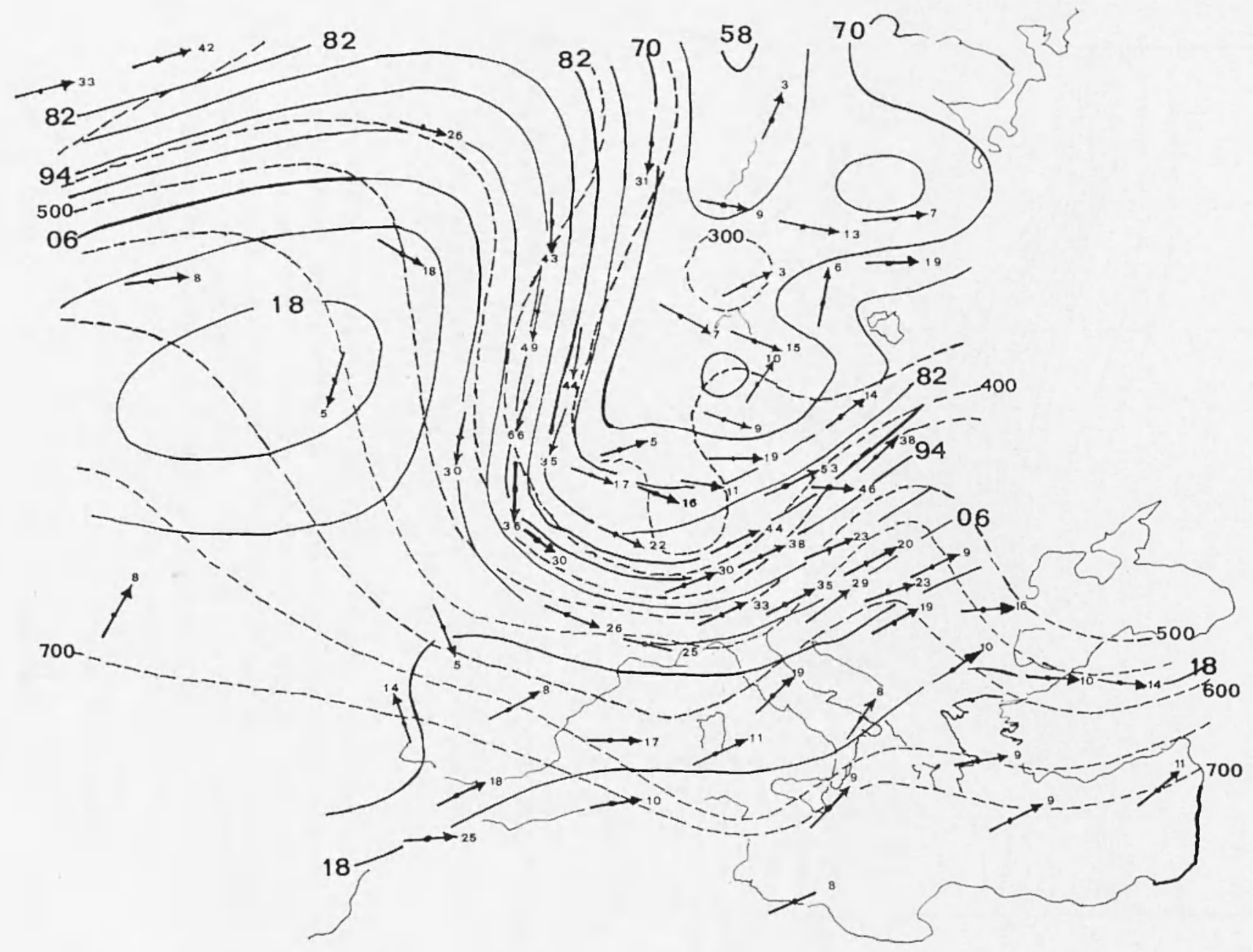

Fig. 4.7 - Isoentropic analysis on the $300 \mathrm{iK}$ potential temperature surface at $0000 \%$ of February $3,1969$. Full line: Montgomery stream function at $60 \times 10^{5} \mathrm{~cm}^{2} / \mathrm{sec}^{2}$ interval. Dashed line: pressure at $50 \mathrm{nıb}$. interval (BUzzI-RIzzI, 1975) $\left(^{3}\right.$ ). 


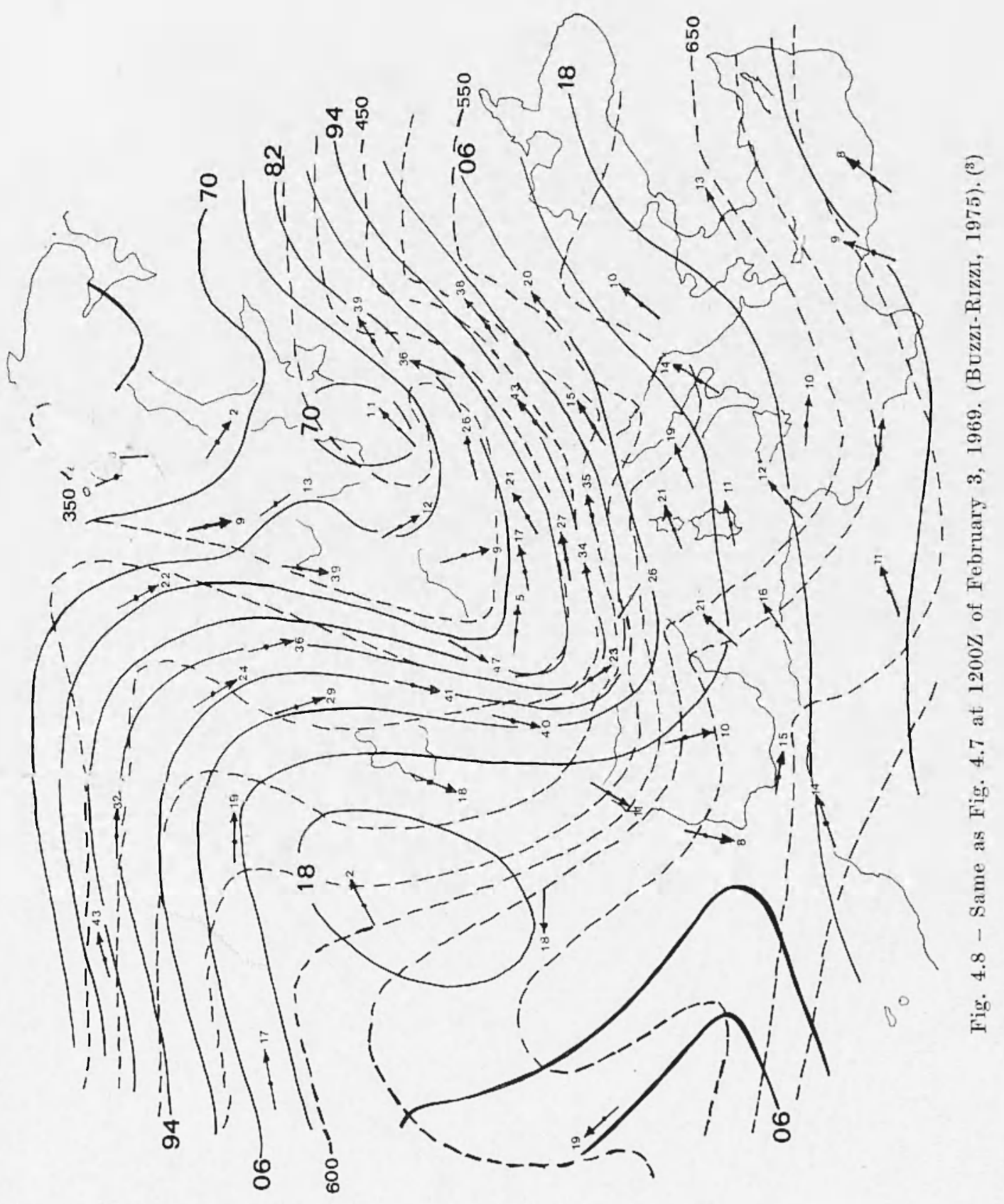




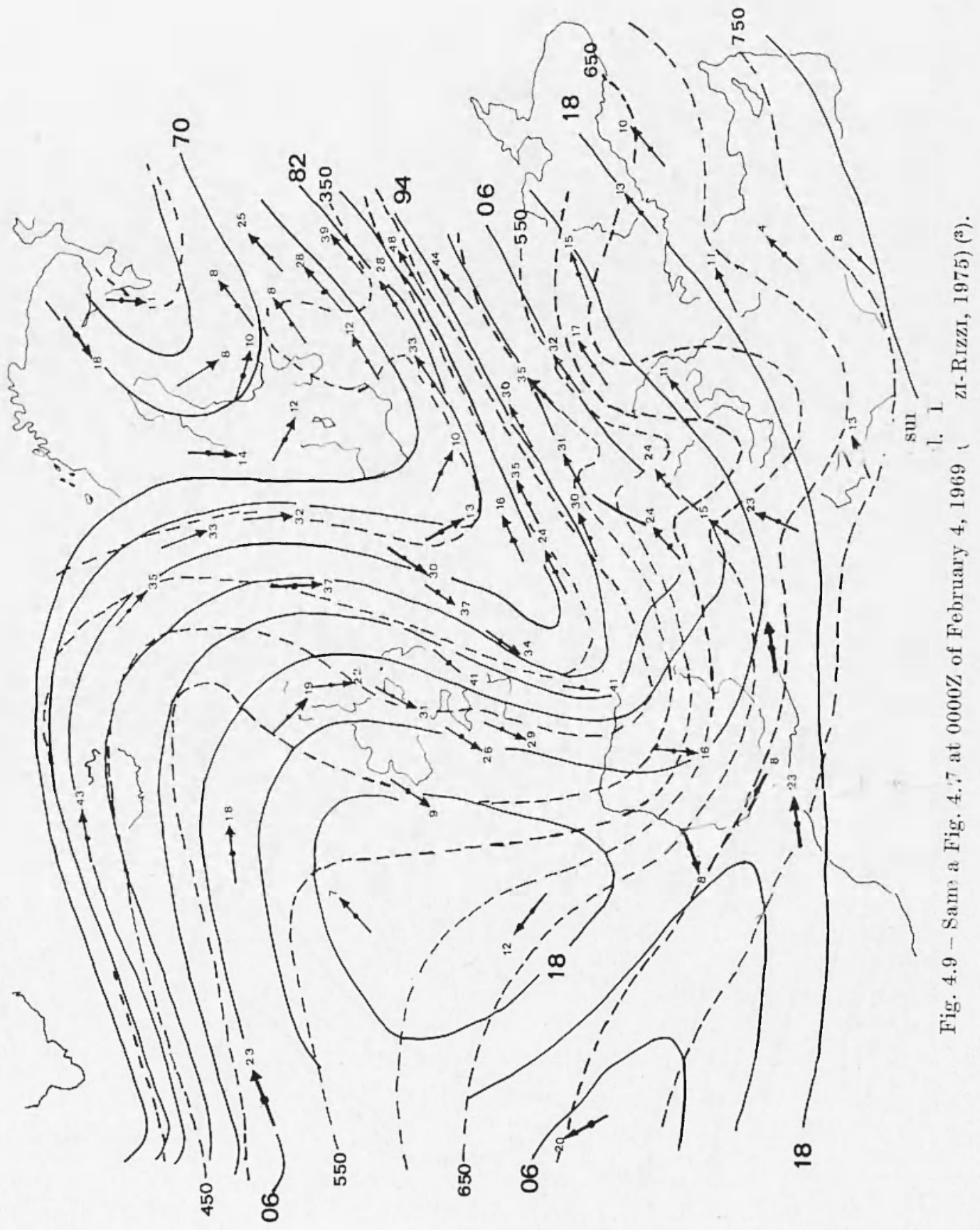




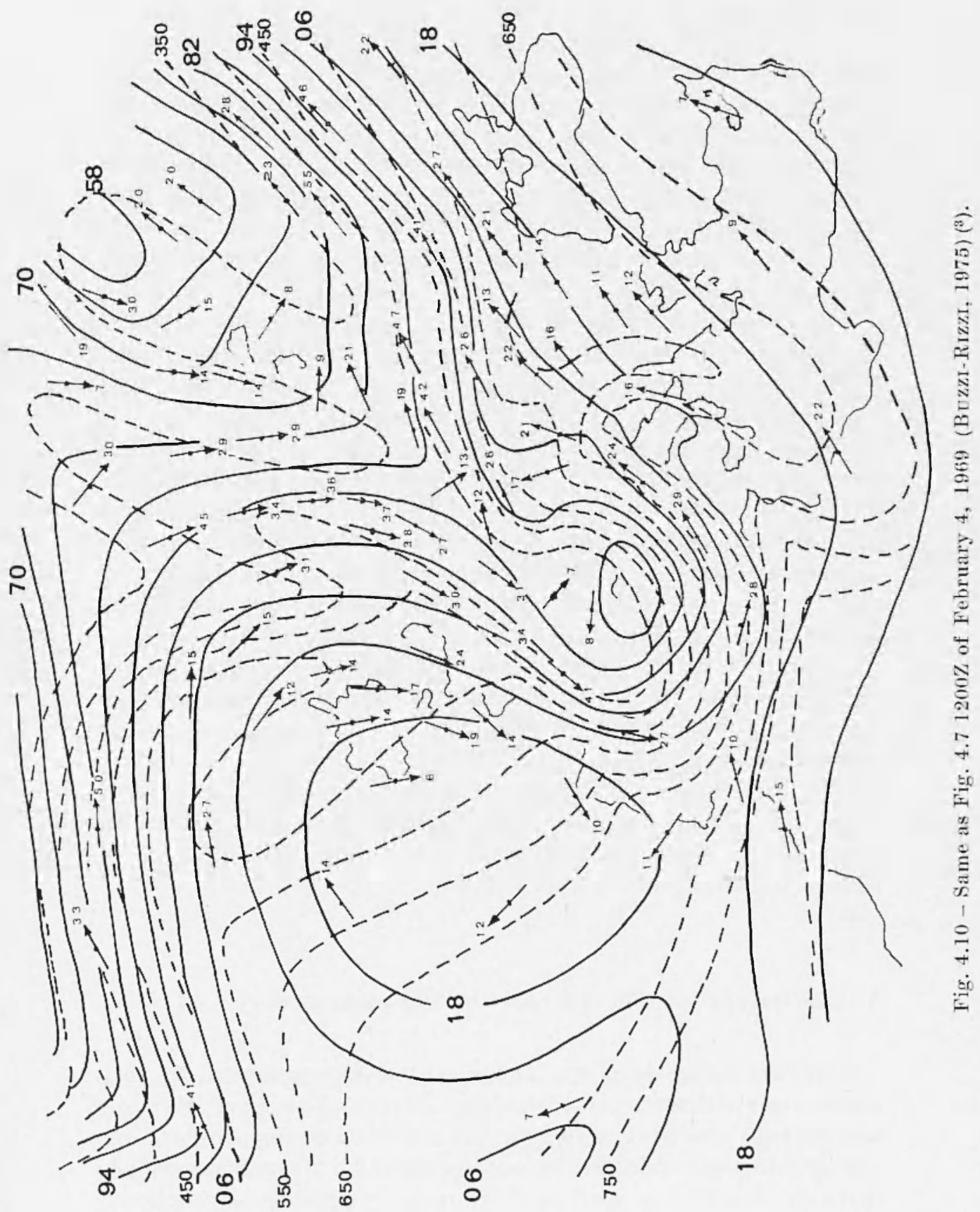


other words, the baroclinic instability determines when and the mountains determine where the cyclone will form" $\left({ }^{9}\right)$.

Once again the reader is invited to notice that the kind of events Danielsen is referring to are very strong, Mediterranean-scale cyclone formations and not simple generations of baric Lows restricted to the Gulf of Genoa. Howevor, even when the baric feature is of such a space as to justify the use of geostrophic approximation, the appearance of strong non-geostroplic modulations makes the interpretation of fields not completely trustworthy near a mountain range. In this ase the interpretation of even sophisticaterl, quasi-geostrophic maps should be made with some caution.

The descent of the jet, its interaction with the $A \mathrm{l} p s$, the penetration between the Alps and the Pyrenees and the final realjustment in the barocinice region South of the Alps are all processes that should be investigated in more detail.

Since the amount of data and work required by isoentropic and trajectory analysis is considerable, indirect evidence of the relevance of "jet phenomenology" has, for the moment, to be looked for. I possible source of information is the statistical analysis of correlation between cyclogenesis events and the intrusion of stratospheric tracers such as ozone and raclioantive materials. This approach is presently being tried by T. Nammi, $A$. Trevisan, $O$. Vittori and the author ${ }^{(26)}$ by means of estimating cross-correlation between Ozone-concentration (whose enhancement is considered representative of tropopause folding) at a ground station (in Sardinia) and a parameter chosen as representative of cyclogenesis.

Obvious difficulties in the choice of the "representative parameter" cause the results to remain inconclusive. Direct tracking of stratospheric tracers would be really helpful in order to give an incentive to future work in this direction.

\section{כ.1 FLOW PAST AN ISOLATED TOPOGRAPIIC OBSTACLIS}

Besides being steep, the barrier of the Alps is limited in horizontal extent. A realistic model of flow past the $A l p s$ should therefore include both effects of "flow over" and effects of "flow around" the barrier. The extreme diffieulty of the resulting mathematical problem is clearly shown by an analysis of the vorticity equation for a uniform- 
ly rotating, homogeneous incompressible flow (every "thermodynamic complication" has been left out):

$$
\underset{\rightarrow}{\mathrm{D}_{\mathrm{t}} \omega}=(\underset{\rightarrow}{\omega} \cdot \nabla) \underset{\rightarrow}{\mathrm{v}}+\underset{\mathrm{f}}{\partial_{\mathrm{z}} \mathrm{v}}
$$

where

$$
\begin{aligned}
& \omega=\nabla \cdot \vec{v} \text { is the velocity; } \\
& \overrightarrow{\mathrm{v}} \text { is the vorticity vector; } \\
& \mathrm{f} \text { is the Coriolis parameter; } \\
& z \text { is the vertical coordinate; } \\
& \mathrm{D}_{\mathrm{t}} \text { is the "advective" derivative; } \\
& \nabla \text { is the "del operator". }
\end{aligned}
$$

It is not difficult to verify that the generation of secondary vorticity gives rise to "secondary flows", in the proximity of the obstacle,

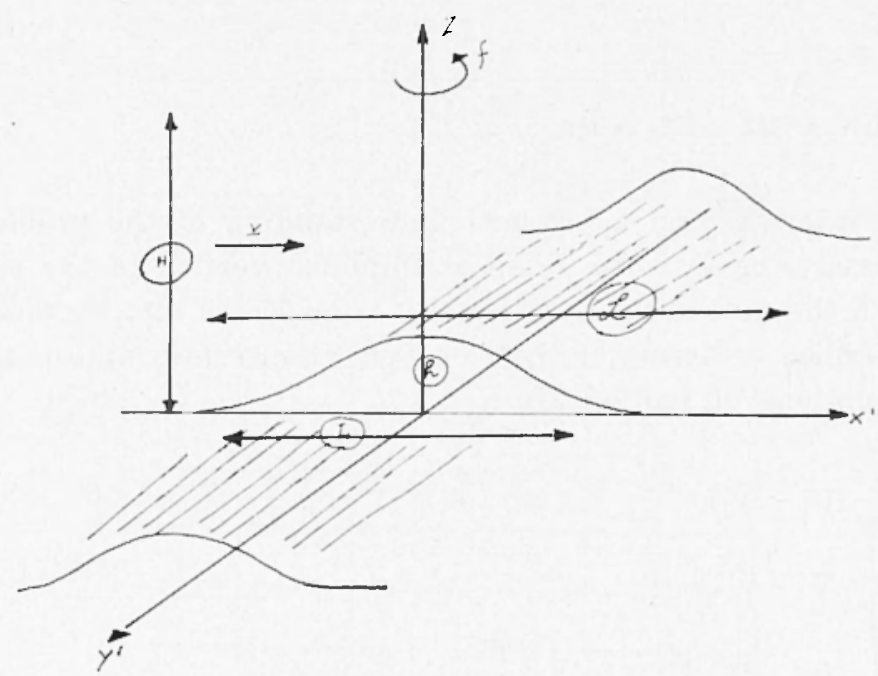

Fig. 5.1 - Scheme of the model flow over a finite amplitude ridge.

which are essentially three-dimensional. Fven if a perturbative approach permits the production of simplified formulas for the generation of secondary vorticity (see for example $\left({ }^{21}\right)$ and $\left({ }^{23}\right)$ ) the problem in question camnot be treated in a satisfactory way, neither analytically nor numerically. 
The only way of obtaining useful information from the equations of fluid motion past obstacles is to submit the motion itself to the constraint of two-rlimensionality. In the case of geophysical flow past obstacles this can be clone in two essentially different ways. The topographic obstacle can be considered:

(i) as being of infinite length in one horizontal direction (llow over a rillge);

(ii) as being infinitely extended and homogeneous along the vertical (flow around a columnar obstacle).

If the rotation of the earth is neglected, the vorticity is seen to be conserved (see equation [5.1.1]). This drastic simplification allows for the application of powerful analytical (and numerical) techniques. For example, the problem of stratified, stealy flow over a finite amplitude rilge can, in certain cases, be solved in closed form (see $\left(^{38}\right)$ ). The insertion of the Coriolis term in the equations of motion creates some difficulties that are partially discussed in what follows.

\subsection{Flow oler tile Alps}

In order to gain a physical understanding of the problem it is worth analysing in some detail a simplified version of the equations in which the flow is steady, viscosity is neglected and thermal effects are described in terms of the so-called "Boussinesq approximation". The equations of motion are:

$$
\left\{\begin{array}{l}
\left(\mathrm{v}^{\prime} \cdot \nabla^{\prime}\right) \mathrm{v}^{\prime}+\nabla p^{\prime}+\mathrm{f} \hat{\mathrm{k}} \times \mathrm{v}^{\prime}-\frac{g}{T_{u}} T^{\prime} \hat{\mathrm{k}}=0 \\
\nabla^{\prime} \cdot \mathrm{v}^{\prime}=0 \\
\left(\mathrm{v}^{\prime} \cdot \nabla^{\prime}\right) T^{\prime \prime}+w^{\prime}\left(\frac{\mathrm{d} \bar{T} T^{\prime}}{\mathrm{d} z^{\prime}}+\frac{\mathrm{g}}{c p}\right)=0
\end{array}\right.
$$

where $\nabla$ is the "clel operator" in terms of the $x^{\prime}, y^{\prime}, z^{\prime}$ coordinates represented in Fig. $5.1 ; \mathrm{k}$ is the vertical unit vector; $\mathrm{f}=2 \Omega \sin \theta$ is the "Coriolis parameter" ( $\Omega$ is the angular velocity of the earth); $g$ is the gravity aceeleration; $T_{m}$ is a reference temperature; $c p$ is the constant pressure specific heat of the atmosphere; $v^{\prime}$ is the velocity; $y^{\prime}$ is the pressure; $T^{\prime}$ is the temperature. 
Appropriate seale-analysis in terms of typical parameters:

$H$ a typical space-scale of modulation of the flow along the vertical;

$I$ a typical space-scale of morlulation of the flow along the horizontal $x^{\prime}$-direction;

$V$ a typical flow velocity $\equiv$ the velocity of unclisturbed flow at $x=-\infty$;
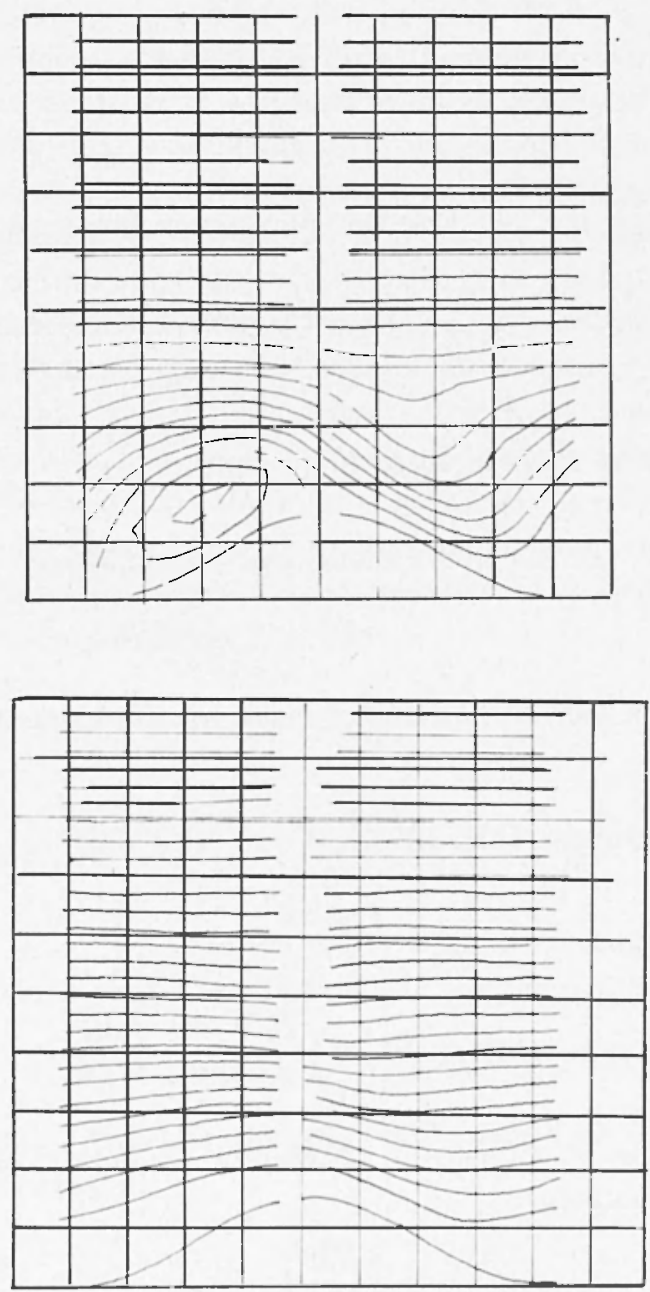

Fig. 5.2 - Streamlines for viscous flow (TEBajoj 1974) $\left({ }^{34}\right)$. 
allows us to write non-dimensional equations that satisfy the balances of momentum (eq. [5.2.1]), continuity (eq. [5.2.2]), heat transfer (eq. [5.2.3]) and a homogeneity along the ridge. The explicit form of such equations is:

$$
\begin{aligned}
& \mathrm{R}_{0}\left(u \partial_{\mathrm{x}}+w \partial_{\mathrm{x}}\right) u-v=-\partial_{\mathrm{x}} \varphi \\
& \mathrm{R}_{0}\left(u \partial_{\mathrm{y}}+w \partial_{\mathrm{z}}\right) v+u=-\partial_{\mathrm{y}} \varphi \\
& \delta^{2} \mathrm{R}_{\mathrm{o}}\left(u \partial_{\mathrm{x}}+w \partial_{\mathrm{z}}\right) w=-\partial_{\mathrm{z}} \varphi+T \\
& \partial_{\mathrm{x}} u+\partial_{\mathrm{z}} w=0 \\
& \mathrm{R}_{0}\left(u \partial_{\mathrm{x}}+w \partial_{\mathrm{z}}\right) T+s^{2} w-0
\end{aligned}
$$

where:

$x=\frac{x}{L}, y=\frac{y^{\prime}}{L}, z=\frac{z^{\prime}}{H}$ are the non-dimensional space-coordinates: $u=\frac{u^{\prime}}{V}, v=\frac{v^{\prime}}{v} ; w=\frac{w^{\prime}}{H / L V}$ are the non-dimensional velocity components;

$\varphi=\frac{p}{\mathrm{f} L V}$ is the non-dimensional pressure;

$T=\frac{T^{\prime}}{\left(\frac{L \mathrm{f} V^{\prime} T_{m}}{H g}\right)}$ is the non-dimensional temperature.

The flow is seen to be characterized by the three non-dimensional numbers:

$$
\begin{aligned}
& \text { Rossby number } \quad R_{0}=\frac{V}{\mathrm{f} L} ; \\
& \text { aspect ratio } \quad \delta=\frac{H}{L} \text {; } \\
& \text { stratification parameter } \left.\mathrm{S}^{2}=\left(\frac{H}{L}\right)^{2}-\frac{\mathrm{g}}{T_{m}} / \frac{\mathrm{d} \bar{T}^{\prime}}{\left.\mathrm{d} z^{\prime}+\frac{\mathrm{g}}{c q}\right)}\right)_{\mathrm{f}^{2}} \text {. }
\end{aligned}
$$

The role of the stratification parameter is better understood if it is written in the form:

$$
\mathrm{S}=\frac{\left(\frac{N H}{\mathrm{f}}\right)}{L}-\frac{L_{\mathrm{R}_{\mathrm{o}}}}{L}
$$


where:

$$
\begin{aligned}
& N^{2}=\frac{g}{r_{m}}\left(\frac{\mathrm{d} \bar{T}}{c z}+\frac{\mathrm{g}}{c p}\right) \text { is the "buoyancy frequency; } \\
& L_{\mathrm{R}_{\mathrm{o}}}=\frac{N H}{f} \text { is the "Rossby rarlius of deformation". }
\end{aligned}
$$

The Rossby rarlius of reformation represents a typical spacescale of readjustment to geostrophic equilibrium of a perturbed flow. It is seen to depend critically both on the stratification of the flow $N$ and on the total depth $H$ of the layer of fluid interested in the process. In the proximity of the rilge the horizontal space-scale of modulation of the flow $L$ can be assumerl to coincirle with the extent of the rilge $L$. The interpretation of the parameter $H$ is more problematic. The usual assumption is that $H$ coincides with the depth of the entire troposphere, but in the presence of secondary flows and/or particular stratification properties of the basic flow (the case of an incoming cold front may well belong to this class!) the typical scale $H$ assumes a different significance. Investigation of this mathematical problem by means of perturbative analysis has been systematically performer by Merkine $\left.{ }^{24}\right)$. Application of the bounclary conclitions for inviscial flow to equations [5.2.4-8] causes the appearance of a fourth non-rlimensional number characterizing the flow:

$$
\alpha=\frac{\hbar}{H}
$$

The condition for the flow not being blockerl appears to be:

$$
a s<1
$$

that simply means that the slope of the particle-trajectory $\frac{H}{L_{\mathrm{R}_{0}}}$ must exceel the slope of the barrier $\frac{h}{H}$ in order that the flow may overcome the rirlge. The non-rlimensional parameter as can be more significantly written as:

$$
a s=\frac{\mathbf{h}\left(\frac{N H}{\mathbf{f}}\right)}{H}-\frac{\left(\frac{N h}{\mathbf{f}}\right)}{L}
$$


that confirms what was mentioned before: the height of the layer that is physically relevant in the phenomenon of blocking is $h$ and not $H$. Another interesting consequence of the perturbative approach is that since the potential energy required to overcome the barrier is produced at the expense of thermal energy the region of the mountain tends to be cooler than further upstream and downstream. For the presence of this horizontal gradient of temperature, in geostrophic approximation, a thermal wind along the ridge is required. It is interesting to notice that similar considerations were put forward, on a different basis, by Radinovic in his paper about the graphic prediction of cyclogenesis $\left(^{28}\right)$.

Use of numerical integration schemes permits us to investigate flows even more complicated than those represented by equations [5.2.4-8]. A numerical model for flow over a ridge, including the effects of viscosity in the form of an Ekman boundary layer, has been developed by C. Tebaldi $\left({ }^{34}\right)$.

Steady state solutions are obtained solving the time-dependent problem of the motion forced by an imposed pressure gradient along the ridge.

The model confirms the role played by stratification in producing blocking, but stresses the importance of non-linear effects in relaxing the constraints imposed by stratification itself, as clearly shown in fig. 5.2, where the streamlines for flows of different Rossby number are shown. It can easily be seen that alvective terms drastically reduce the blocking action of the barrier.

As the anthor points out, however, the cases shown have a prescribed temperature distribution at ground level (constant temperature in most cases) (*) and comparison with theoretical solutions by Nerkine should therefore be made with some care since the mechanism of the production of energy for overflow is essentially different. Introduction in the numerical model of more realistic conditions for temperature will permit us to obtain extremely interesting results for the thermodynamic part too.

${ }^{*}$ ) It is not possible to say how much of the secondary eirculation is due to blocking and how much to thermal circulation. 


\subsection{Flow Around tire Alps}

The implication of theoretical studies of rotating flows around columnar obstacles are well illustrated by the simple case of a strictly two-dimensional flow of a homogeneous incompressible fluid.

It is not difficult to show that the solution for the velocity field of the steady flow of a homogeneous incompressible fluid uncler the constraint of two-dimensionality, is not affected by the presence of a uniform rotation of the whole system. For example the familiar solution for flow around a circular cylinder (illustrated in Fig. 5.3),

$$
\psi(r, \vartheta)=-v\left(r-\frac{\mathrm{a}^{2}}{r}\right) \sin \vartheta
$$

where:

$\psi \quad$ is a stream-function for the velocity field;

$r, \vartheta$ are cylindrical coordinates;

a is the radius of the cylinder;

$v \quad$ is the umperturbed stream velocity

is also true when the flow is rotating.

The effects of rotation can easily be shown to appear in the pressure distribution:

$\pi(\delta, \vartheta)=\pi_{\infty}+\left(2 \frac{\cos 2 \vartheta}{\delta^{2}}-\frac{1}{\delta^{4}}\right)-\frac{1}{\mathrm{R}_{0}}\left(\delta-\frac{1}{\delta}\right) \sin \vartheta$

where:

$\pi-\frac{p}{\varrho^{2 / 2}}$ is the non-dimensional pressure;

$v \quad$ is the dimensional pressure;

$Q \quad$ is the density;

$\pi_{\infty}$ is the pressure at $x=-\infty$

$\delta=\frac{r}{a} \quad$ is the non-dimensional radial coordinate;

$R_{0}=\frac{y}{a f} \quad$ is the "obstacle Rossby number". 


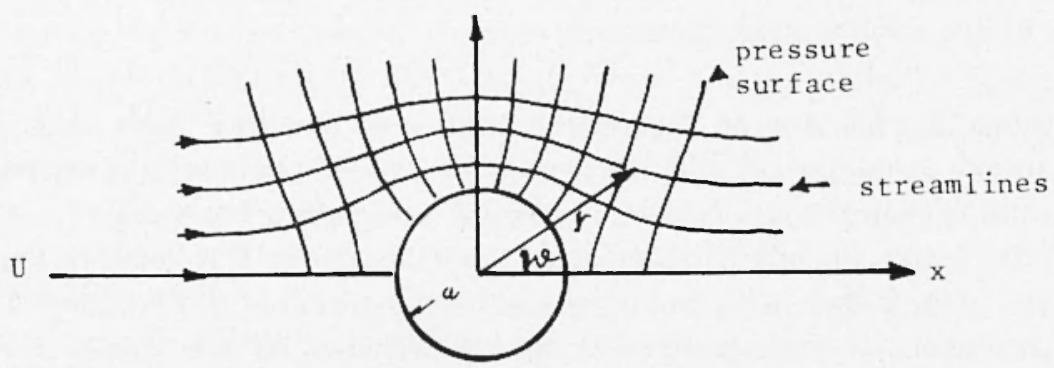

(a)

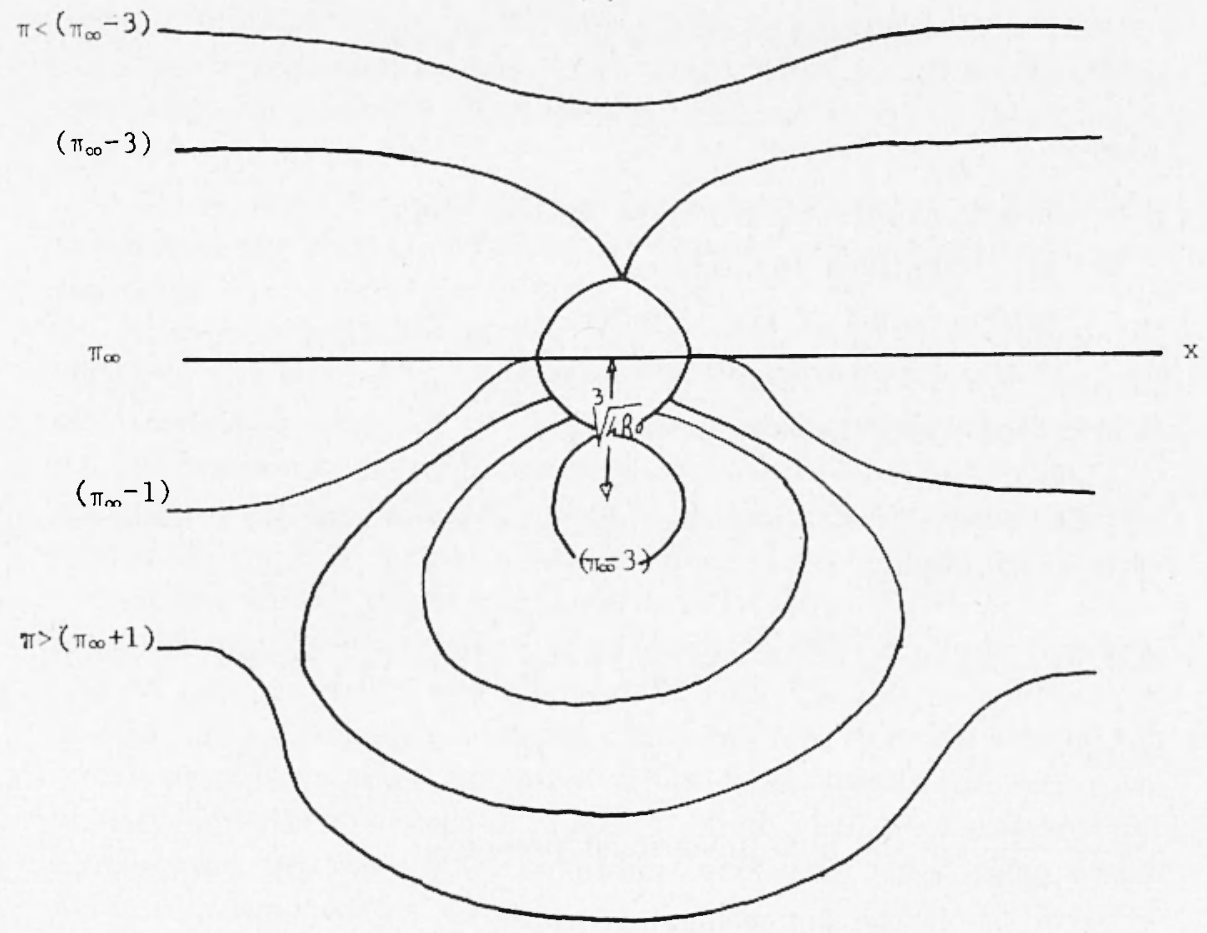

(b)

Fig. 5.3 - (a) Flow around a circular cylinder.

(b) Non-dimensional pressure distribution in rotating, two-dimensional flow past a cylinder. 
Is can easily be seen the pressure field [5.3.2] consists of two parts:

(i) an inertial "near field" that coincides with the pressure field in the flow without rotation;

(ii) a geostrophic "far field" (the pressure lines are parallel to the streamlines) that gives no component of velocity normal to the wall of the obstacle.

The relative "weight" of the two parts of the solution is determiner by the "obstacle Rossby number". Of extreme interest is the resulting pressure pattern (Fig. 5.3) that shows an asymmetric HighLow distribution: the similarity to the isobar distribution near the dlps in connection with the formation of local pressure lows in the Gulf of Genoa is really impressive. The similarity becomes more marked if other details (lilie the ar(-shape of the $\mathrm{Alps,}$ eventual free-streamline separation, a different attack angle of the flow etc...) are introduced.

The inclusion of inertial effects, even in the simple two-dimensional flow, appears to stress particulars of the near field that camnot be understood in the light of quasi-geostrophic theory.

Perturbative analysis of stratified, rotating flow around a cylinder performed by $\mathrm{N}$. G. Hoggr ${ }^{(20)}$ confirms the results of the study of the two-dimensional case. Fig. 5.4 shows the effects of the adrective terms on temperature distribution. The typieal High-Low asymmetry is fairly evident.

Observation of cloud patterns from meteorological satellites has brought to the attention of physicists a number of examples of flow past geophysical obstacles which has many features in common with laboratory flows. In excellent review of the subject has been publisher by E. Rupert and R. Wille ( $\left.{ }^{31}\right)$. A well known case is that of the flow past Jan Majen island that exhibits a series of vortices arranged in a configuration extremely similar to the Von Karman rortex street of two-rlimensional flow past obstacles at a low Reynolds number. This connection between laboratory and geophysical flows is still relatively unexplored, except for isolated contributions (see, for example (22)), although the interesting aspects of the problem have been pointer out on varions occasions. In important fact is that in the $A$ tmosphere and the Ocean Reynolds numbers between $10^{6}$ and $10^{8}$ are quite common, while laboratory experiments at Re 107 are still an exception $\left({ }^{30}\right)$. 
However, the analogy between laboratory and geophysical flows should be considered with are for several different reasons. Firstly, flows in the geophysical seale are very often dominated by the rotation of the earth and thermodynamic processes.

On the other hand, even if the modifying factors cited are taken into account, it is not easy to see why geophysical flows should reproduce a dynamics that is typical of strongly controlled, laboratory flows. This, for example, is the case of the flow past Jan Majen, men-
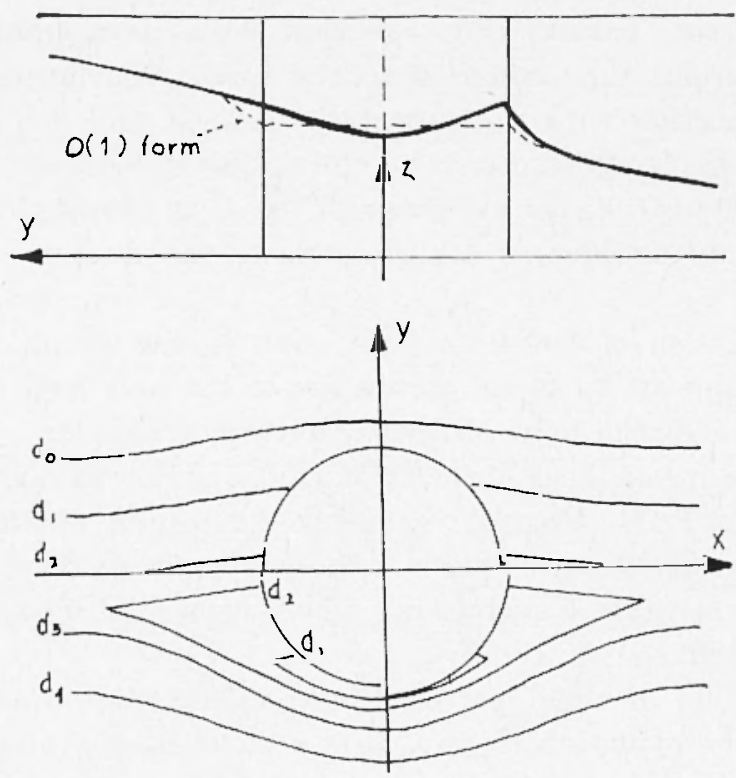

Fig. 5.4 - Sketched form of an isotherm in the $y \cdot z$ plane looking downstream and a horizontal plane from above showing the $O(\varepsilon)$ effects $\left(\mathrm{C}^{\circ}(z)\right.$ O) (HoGG, 1972) $\left({ }^{20}\right)$

tioned above: the Von Karman vortex street should be produced by a $2000 \mathrm{~m}$ mountain acting on a tropospheric shear flow; but Von Karman vortices are typical of two-dimensional flow! An obvious source of quasi-two-dimensional behaviour in a three-dimensional flow is stratification: if the height of an isolated obstacle exceeds a "stratification scale", the obstacle can be "seen" as two-dimensional by the fluid flowing in limited layers. This kind of phenomenology is 
more easily investigated in the ocean where isolated islands are more likely to resemble colummar obstacles (see $\left({ }^{39}\right)$ ).

Since the Alps are more similar to an isolated obstacle than an infinite ridge, a strongly stratified fluid might, in its lower layers, tend to flow around and not over the barrier (this kind of behaviour has been mentioned in 4.1 in connection with Egger's work). If this is the case, even the phenomenology of separation should resemble that of classical two-dimensional flow past obstacles. Therefore, under what conditions will a "wake" behind the Alps form? The question has been raised by $J$. G. Charney who pointed out $\left(^{4}\right)$ that, since a Reynolds number for the $A l p s$ can be of the order of $10^{5}-10^{6}$, separation is possible according to traditional criteria. The dynamics of separation involves necessarily non-geostrophic eflects since adverse pressure gradients not allowed in strictly geostrophic flow are required. Either inertial or viscous effects have to be investigated.

\subsection{CoNClusion}

This brief outline of the history of research about the interaction of atmospheric flows with the Alps is of course not exhaustive.

The aim of the work has been simply to show how many interesting physical aspects of the problem still require investigation and to help the interested reader in the formulation of possible research themes.

The general picture that emerges from the preceding Section is the following:

the interaction of large scale meteorological flows with the Alpine barrier produces secondary flows of different horizontal extent, intensity and duration.

When cold flows from the North-West interact with the Alps a relative depression appears in the baric field owing to the flow of cold air through the Rlône Valley.

In a limited number of cases (not more than five per year) the depression-formation extends to the whole region downstream of the $\Lambda$ lps and takes the form of a real cyclonic development with the formation of a region of strong vorticity ("wake"?) through processes still to be understood (separation, baroclinic instability, some other lind of instability ete...). 


\section{REFERENCES}

(1) Bossodasco M., 1948. - "Geof. Pura e Appl.", 11, p. 122.

(2) Bossolasco M., 1952. - "Geof. Pura e Appl.", 22, p. 255.

$\left({ }^{3}\right)$ Buzzr A., Rizzr R., 1975. - "Rivista Italiana di Geofisica", 1, 1. 7.

(4) CHarier J. G., 1973. - Conclusive talk at the Summer School about Meso-seale atmospherie phenomena, "CNR, Lab. I)in. Grandi Masse", Venice.

$\left({ }^{5}\right)$ CENFAX1, 1963. - STR., 4.

$\left({ }^{6}\right)$ CENFAM, 1963. - STR., 5.

(7) ('ENFA.H, 1964. - STR., 6.

$\left({ }^{8}\right)$ Daxiessex E., 1973. - Lecture at the Summer School about Mesoseale Atmospheric Phenomena, "CNR, Lahl. Din. Grandi Masse", Venice.

(9) Daxielsex E., 1973. - Lecture at the Summer School about IIesoscale Atmospherie Phenomena, "(NR, Lah. Din. Grandi Masse". Venice.

$\left({ }^{10}\right)$ Disies E., 1938. - "Ann. Hydro Mar. Met.", 466.

(11) Enemax W., 1963. - Technical Note n. 6; Deutseher Wetterdienst.

${ }^{(12)}$ EGger J., 1972. - "Tellus", 24, 4.

(13) Egger J., 1972. - "Beiträge zur Physik des Atmosphäre", 45, p. 320.

(ii) vox Frcher II., 1920. - "Met. Zeit", 37, p. 360.

$\left.{ }^{15}\right)$ Gвurcik P., 1960. - "Geof. Pure o Appl.", 238.

${ }^{(10)}$ Glessox T. A., 1953. - "Archiv. Met. Geopl.. Bioklim.", p. 153.

(17) Gueson T. A., 1956. - "Archiv. Met. Geoph. Bioklim.", p. 185.

${ }^{(18)}$ Gonev N., "Journ. Appl. Met.".

(19) IIOGG N. G., 1973. - “J.F.MI.", 58, 5, 1. 7.

${ }^{(20)}$ HoGi N. G., 1972. - "Geopl.. Fl, Dyn.", 4, p. 55.

(21) Hordock .l. II., LaksmimaraYaxa B., 1973. - "Ann. Rev. Fl. Meeh.".

$\left({ }^{2 .}\right)$ Hubert I. F., Krueger A. F., 1962. - "Mon. Wea. Rev.", 90, p. 457.

${ }^{(23)}$ Млnzis I., 1966. - “Trans. A.S.M.E.", D) 88, p. 533.

(24) Merkise I. - Private communication.

${ }^{(25)}$ Moxtalto M., Pellegrixi E., Rivosecchi L., 1967. - "CENPAM CP", 92.

(26) Naxir T., Speranza A., Trevisan A., Vittori 0., 1975. - "Archiv Für Met. Geophyss. und Bioklinatologie".

${ }^{(27)}$ Radrxovici D., 1960. - VI Congrès Intern. Hét. Alpine, Bled, Yugoslavie.

${ }^{(2 *)}$ Radinovici D), 1965. - "Archiv. Met. Geopl. Bioklim.", 279.

(29) Reiter E. R., 1963. - "Jet Stream Meteorology", Chicago Univ. Press.

${ }^{(30)}$ Rosino R., 1961. - “J. Fl. Mech.", 10, p. 345. 
(31) Rupert F., Wille R., 1972. - “Ann. Rev.", 71 Dyn.

(32) Sherag R., 1965. - "Proc. Int. Symp. Dyn. Marge-Scale", "Proc. in the Atm.", Moscow.

$\left({ }^{33}\right)$ Sutchiffe R. C., 1960. - "Met. Abh. fr. Univ. Berlin", 135.

(34) Temaldi C. - Private communication.

(35) Urbaxi M., 1956. - "Riv. Met. Aer.", 1, 3.

(36) Urbaxi M., 1957. - "Riv. Met. Aer.", 3, 15.

(37) Visconti I., Pirro R., Simonet't D., Baroni A., 1965. - "CENFAM S'TR", 8.

${ }^{(38)}$ Yнi C. S., 1965. - Dynamics of non-homogeneous fuid. Macmillan N.Y.

${ }^{39}$ ) Wunsil C., 1972. - "Tellus", 24, p. 350. 